\title{
Evidence of an anti-inflammatory toll-like receptor 9 (TLR 9) pathway in adipocytes
}

\author{
Miriam Thomalla¹, Andreas Schmid¹, Elena Neumann², Petra Ina Pfefferle ${ }^{3}$ Ulf Müller-Ladner², Andreas Schäffler ${ }^{1}$ \\ and Thomas Karrasch1
}

\begin{abstract}
1Department of Internal Medicine III, Giessen University Hospital, Giessen, Germany 2Department of Rheumatology and Clinical Immunology, University of Giessen and Kerckhoff Clinic, Bad Nauheim, Germany ${ }^{3}$ Comprehensive Biomaterial Bank Marburg (CBBMR), Philipps-University of Marburg, Marburg, Germany
\end{abstract}

Correspondence should be addressed to T Karrasch: thomas.karrasch@innere.med.uni-giessen.de

\begin{abstract}
Adipocytes express various pattern recognition receptors (PRRs) such as Toll-like receptors (TLRs) and actively participate in anti-bacterial and anti-viral host defence. Obesity is associated with adipose tissue PRR expression. The potential role of Toll-like receptor 9 (TLR9) in adipocytes has not yet been investigated. Here, we evaluated TLR9 expression during adipocyte differentiation (AD) of 3T3-L1 adipocytes, in primary murine adipocytes and in different murine and human adipose tissue depots by real-time PCR, immunocytochemistry and immunohistochemistry. TLR9 expression was inhibited using specific siRNA-mediated knockdown, and TLR9 signaling was induced using specific class $\mathrm{A}, \mathrm{B}$ and $\mathrm{C}$ agonistic $\mathrm{CpG}$-oligodeoxynucleotide (ODN) treatment vs ODN controls in 3T3-L1 adipocytes and in primary murine adipocytes from TIrgwt/wt vs TIr9-/- mice. We found that TLR9 gene expression is induced during AD and that TLR9 protein is expressed in murine gonadal and human visceral adipocytes. AD depends on intact TLR9 expression. TIr9-/- mice demonstrate significantly reduced adiponectin serum levels, while siRNAmediated TLR9 knockdown led to reduced adiponectin mRNA expression in adipocytes. TLR9 ligands (CpG-ODNs) inhibit pro-inflammatory resistin secretion in mature 3T3-L1 adipocytes. TIr9-I- as compared to TIr9wt/wt adipocytes exhibit increased resistin and MCP1 secretion and reduced adiponectin secretion into cell culture supernatants, while TLR9 ligands (ODNs) show differential effects in TIr9-/- vs TIr9wt/wt primary murine adipocytes. TLR9 expression is significantly increased in visceral compared to subcutaneous adipose tissue depots in non-diabetic obese patients and correlates with systemic resistin levels in a compartment-specific manner. Thus, adipocytic TLR9 is a putative, new protective factor during (obesity-associated) adipose tissue inflammation.
\end{abstract}

Key Words
- TLR9
- adipocyte
- inflammation
- adipose tissue
- adipokine
- pattern recognition
receptor
- CpG

Journal of Endocrinology (2019) 240, 325-343

\section{Introduction}

The 'obesity epidemic' in Western societies and its associated morbidity and mortality has focused the attention of the scientific community on adipose tissue in health and disease (Abdullah et al. 2011, Shamseddeen et al. 2011). Adipose tissue - via the secretion of hormone-like factors, named adipokines - is increasingly recognized as an endocrine and immunological organ actively participating in homeostatic mechanisms including metabolism and immune function (Schaffler et al. 2005, 2006, 2007). Obesity is associated with a significant pro-inflammatory transformation of the complex cellular environment of adipose tissue 
(encompassing adipocytes, pre-adipocytes, fibroblasts, monocytes, macrophages, endothelial cells and mesenchymal stem cells) in visceral adipose tissue depots in particular (Weisberg et al. 2003, Apostolopoulos et al. 2016), including pro-inflammatory signaling pathway activation in adipocytes themselves (Grant \& Stephens 2015, Caputo et al. 2017). This pro-inflammatory transformation is pathophysiologically relevant, leading to insulin resistance and other associated co-morbidities in obese patients (Gregor \& Hotamisligil 2011).

It has recently been demonstrated that adipocytes express various pattern recognition receptors (PRRs) such as Toll-like receptors (TLRs) and nucleotide oligomerization domain (NOD)-like receptors (Kopp et al. 2010). Pathogen-associated molecules are able to stimulate these receptors, leading to the expression and secretion of pro-inflammatory cytokines/adipokines (Kopp et al. 2010, Bae et al. 2014, Yu et al. 2014, Zhang et al. 2015). Obesity itself appears to be associated with pattern recognition receptor expression and downstream pro-inflammatory signaling activation within adipose tissue depots, and endogenous mediators including long-chain saturated fatty acids (lcSFA) have been demonstrated to induce PRR-dependent signaling in this context (Shi et al. 2006, Kim et al. 2012). Importantly, Lancaster et al. recently demonstrated in a seminal paper that TLR-dependent priming alters cellular metabolism of lcSFAs in bone marrow-derived macrophages (BMDMs). This metabolic reprogramming is a pre-requisite for lcSFA-induced, proinflammatory Jun kinase (JNK) activation in BMDMs (Lancaster et al. 2018).

Recently, it has been shown that cell-free DNA (cfDNA) derived from apoptotic adipocytes and so-called extracellular traps (ETs) derived from macrophages and neutrophil granulocytes are increased in serum in murine obesity models as well as in human obese patients (Nishimoto et al. 2016, Revelo et al. 2016). cfDNA and ETs induce a TLR9-dependent pro-inflammatory transformation of visceral adipose tissue depots, which is mediated via adipose tissue-resident macrophages and liver-resident plasmacytoid dendritic cells (Ghosh et al. 2016, Revelo et al. 2016). TLR9-dependent production of interleukin-1 $\beta$ (IL-1 $\beta$ ) by Kupffer cells induces hepatic steatosis, inflammation and fibrosis in mice fed a cholinedeficient amino acid-defined (CDAA) diet, a murine model of non-alcoholic steatohepatitis (NASH). In this model, Tlr9-/- mice are protected from CDAA-induced steatohepatitis and fibrosis and have less insulin resistance than TLR9wt/wt mice (Miura et al. 2010). However, Tlr9-/mice fed with a high-fat diet exhibit increased body weight, reduced glucose tolerance and insulin resistance as compared to WT animals (Hong et al. 2015).

Adipocytes themselves have been demonstrated to express functional TLR9 receptors in few preliminary reports; however, no data are available on the contribution of adipocytic TLR9-dependent signaling to (visceral) adipose tissue inflammation. Therefore, our current work aims to provide a detailed study of adipocytic TLR9 receptor expression and signaling activity. We demonstrate that TLR9 expression is induced during adipocyte differentiation and that adipocytic lipid accumulation - in turn - depends on functional adipocytic TLR9 signaling. In mature adipocytes, different TLR9 ligands exert antiinflammatory effects and inhibit adipocytic glucosetransporter expression in vitro. Finally, TLR9 expression in different adipose tissue depots correlates with systemic pro-inflammatory resistin serum levels in female obese patients undergoing bariatric surgery in a depot-specific manner.

Our data imply adipocytic TLR9 signaling as a new contributor to adipose tissue physiology. Since adipocyte-specific IKK $\beta$ signaling suppresses adipose tissue inflammation (Kwon et al. 2014), TLR9-mediated anti-inflammatory signaling potentially serves important homeostatic functions limiting the pathophysiologic sequelae (e.g. insulin resistance) associated with metabolic inflammation, especially in the context of obesity and metabolic syndrome.

\section{Materials and methods}

\section{T3-L1 adipocyte cell culture and stimulation experiments}

Murine 3T3-L1-pre-adipocytes (Green \& Kehinde 1975) were cultured at $37^{\circ} \mathrm{C}$ and $5 \% \mathrm{CO}_{2}$ in DMEM (Dulbecco's Modified Eagle Medium, Biochrom AG, Berlin, Germany) that was supplemented with $10 \%$ newborn calf serum (NCS; from Sigma-Aldrich) and 1\% penicillin/streptomycin (PAN, Aidenbach, Germany). The cells were then differentiated into mature adipocytes at confluence by DMEM/F12/glutamate-medium (Lonza, Basel, Switzerland) supplemented with $20 \mu \mathrm{M}$ 3-isobutylmethyl-xanthine (Serva, Heidelberg, Germany), $1 \mu \mathrm{M}$ corticosterone, $100 \mathrm{nM}$ insulin, $200 \mu \mathrm{M}$ ascorbate, $2 \mu \mathrm{g} / \mathrm{mL}$ apo- transferrin, 5\% fetal calf serum, $1 \mu \mathrm{M}$ biotin, $17 \mu \mathrm{M}$ pantothenic acid, 1\% penicillin/streptomycin (all from Sigma Aldrich) and $300 \mu \mathrm{g} / \mathrm{mL}$ Pedersen-fetuin (MP Biomedicals, Illkirch, France) (Zaitsu \& Serrero 1990, 
Bachmeier \& Loffler 1994) for 9 days using a slightly modified protocol as reported in the literature (Green \& Meuth 1974, Green \& Kehinde 1975, 1979, Cornelius et al. 1994, MacDougald \& Lane 1995). The phenotype was controlled by light microscopy (appearance of extensive accumulation of lipid droplets). Mature adipocytes at day 8 of differentiation were used for stimulation experiments following overnight incubation under serum-free culture conditions. CpG oligodeoxynucleotides (ODNs; classes $\mathrm{A}, \mathrm{B}, \mathrm{C}$ and the respective control ODNs) were purchased from InvivoGen (San Diego, CA, USA) and dissolved in $\mathrm{H}_{2} \mathrm{O}$ according to manufacturer's recommendations. Differing doses of CpG-ODNs were used for overnight (18h) stimulation experiments ( $n=6$ wells each). In case of co-stimulation experiments with lipopolysaccharide (LPS; from Sigma Aldrich), pre-incubation (1 h) of 3T3-L1 adipocytes with CpG-ODNs was performed prior to addition of LPS into cell culture supernatants. For all cell culture experiments, LDH (lactate dehydrogenase) concentration was measured in the supernatants (Cytotoxicity Detection Kit, Roche) to exclude any unexpected cytotoxic effects. For siRNA-mediated knockdown of TLR9, 3T3-L1 cells were repeatedly transfected with anti-TLR9 siRNA during hormonally induced adipocyte differentiation at days $0,3,6,8$ for $3 \mathrm{~h}$ each, using X-tremeGENE siRNA Transfection Reagent (Roche Diagnostics $\mathrm{GmbH}$ ). A pool of 3 TLR9 siRNAs (\# 175054, 175055, 175056, Ambion Life Technologies) with a final concentration of $100 \mathrm{nM}$ was used (\# 175054: sense: 5'-GCUAUAAUGGUAUCACCAACtt-3'; \# 175055: sense: 5'-GCUCUCUCCAUACACUGAAtt-3'; \# 175056: sense: 5'-GCGAGAACUUUCUCUAUGAtt-3'). Control cells were transfected with $100 \mathrm{nM}$ non-targeting siRNA (nt siRNA) (Silencer Select Negative Control siRNA \#1, Ambion Life Technologies).

\section{Isolation and cell culture of primary murine adipocytes}

For primary cell culture, fresh gonadal and subcutaneous adipose tissue was cut into small pieces and treated with $0.225 \mathrm{U} / \mathrm{mL}$ collagenase NB 6 (\#17458, SERVA Electrophoresis; Heidelberg, Germany) at $37^{\circ} \mathrm{C}$ for a maximum of $60 \mathrm{~min}$. Digestion process was stopped by adding buffer (PBS containing 0.5\% BSA and $2 \mathrm{mM}$ EDTA). Cell suspension was filtered by $120 \mu \mathrm{m}$ nylon mesh to eliminate undissolved tissue. Pre-adipocytes were separated from adipocytes by $10 \mathrm{~min}$ centrifugation at $300 \mathrm{~g}$ and $4^{\circ} \mathrm{C}$. Magnetic labeling plus depletion of nonadipocyte progenitor cells was done according to the

(C) 2019 Society for Endocrinology Published by Bioscientifica Ltd. Printed in Great Britain manufacturer's instructions (Adipose Tissue Progenitor Isolation Kit mouse, MACS Miltenyi Biotec), as well as magnetic labeling and positive selection of adipocyte progenitor cells. Isolated pre-adipocytes were seeded at a density of $2.03 \times 10^{4} \mathrm{cells} / \mathrm{cm}^{2}$ in DMEM (Dulbecco's Modified Eagle Medium, Biochrom AG, Berlin, Germany) that was supplemented with $10 \%$ newborn calf serum (NCS; from Sigma-Aldrich) and cultured at $37^{\circ} \mathrm{C}$ and $5 \% \mathrm{CO}_{2}$. Adipocyte differentiation was initiated after cells reached $85 \%$ confluency. Media for hormonal differentiation were supplemented as described above for 3T3-L1 cell-line. Cell phenotype during adipocyte differentiation was monitored by light microscopy. Stimulation experiments were performed with mature adipocytes at day 11 of differentiation providing same conditions as described for 3T3-L1 adipocytes and using corresponding CpG-ODNs, each at a concentration of $20 \mu \mathrm{g} / \mathrm{mL}$. Total RNA, whole cell protein and cell culture supernatants were harvested using All Prep RNA/Protein Kit (Qiagen). LDH (lactate dehydrogenase) concentration was measured in supernatants (Cytotoxicity Detection Kit, Roche) to exclude any unexpected cytotoxic effects.

\section{Isolation of mRNA from human and murine tissues and from murine cells}

Total mRNA was isolated from frozen murine gonadal and subcutaneous adipose tissue, from human visceral and subcutaneous adipose tissue and from isolated murine adipocytes and the stroma-vascular cell fraction (SVC) of adipose tissue. Cell dissociation from frozen murine gonadal and subcutaneous adipose tissue and from human visceral and subcutaneous adipose tissue for mRNA isolation was performed using TRIzol Reagent (Life Technologies $\mathrm{GmbH}$ ) in combination with gentleMACS dissociator and M-tubes (Miltenyi Biotec $\mathrm{GmbH}$ ). For mRNA isolation from isolated murine adipocytes vs the stroma-vascular cell fraction of adipose tissue (SVC), small portions of fresh gonadal and subcutaneous adipose tissue were digested with $0.225 \mathrm{U} / \mathrm{mL}$ collagenase NB 6 (\#17458, SERVA Electrophoresis; Heidelberg, Germany). Adipocytes were then separated from SVC via centrifugation. For deproteination chloroform (ROTH, Karlsruhe, Germany) was added to cell suspensions in TRIzol Reagent. After tissue preparation, mRNA was isolated using RNeasy Mini Kit (Qiagen) including DNase digestion (RNase-Free DNase Set, Qiagen). For mRNA isolation from 3T3-L1 adipocytes, cells were harvested and mRNA was isolated applying RNeasy Mini Kit according to manufacturer's recommendations. 
Quantification of adiponectin, GLUT1, GLUT4, IL-6, MCP-1 and TLR9 mRNA expression in murine 3T3-L1 adipocytes in vitro and ex vivo in murine and human adipose tissues

After isolation of mRNA via RNeasy Mini Kit, gene expression of murine adiponectin, Glucose transporter 1 (GLUT1, SLC2A1), Glucose transporter 4 (GLUT4, SLC2A4), interleukin 6 (IL-6), Monocyte chemoattractant protein 1 (MCP1, CCL2), TLR9 and human TLR9 was quantified by reverse transcription and real-time PCR (RT-PCR) of the corresponding cDNA. Following primer pairs were used:

Murine adiponectin: 5'-AGGGAGAGAAAGGAGATGCAG3'/5'-CAGACTTGGGCTCCCACCTC-3'

Murine GLUT1: 5'-AGCAGAGGCTTGCTTGTAGA-3'/ 5'-AACTCCTCAATAACCTTCTGGGG-3'

Murine GLUT4: 5'-TGGTTCATTGTGGCAGAGC-3'/ 5'-CGTAAGGACCCATAGCATCC-3'

Murine IL-6: 5'-AGTTGCCTTCTTGGGACTGA-3' / 5'-TCCACGATTTCCCAGAGAAC-3'

Murine MCP1: 5'-AGGTCCCTGTCATGCTTCTG-3'/ 5'-TCTGGACCCATTCCTTCTTG-3'

Murine resistin: 5'-TGC TAA GTC CTC TGC CAC GTA-3'/ 5'-TCA ACT GAC CGA CAT CAG GA-3'

Murine TLR9: 5'-CATCTCCCAACATGGTTCTCC-3'/5'GCAGAGAAACGGGGTACAGA-3'

Human TLR9: 5'-CCCCCAGCATGGGTTTCT-3'/5'-TGG AGCTCACAGGGTAGGAA-3'

Expression levels of these genes were normalized to gene expression of glyceraldehyde-3-phosphate dehydrogenase (GAPDH) by using primer pairs:

5'GAGTCCACTGGCGTCTTCAC-3' /5'-CCAGGGGTG CTAAGCAGTT-3' (human) and

5' - TGTCCGTCGTGGATCTGAC - 3' / 5 ' - AGGGAG ATGCTCAGTGTTGG-3' (mouse).

For better visualization of the results, gene expression levels normalized to GAPDH expression levels (TLR9/GAPDH and adiponectin/GAPDH) were multiplied with $10^{6}$ (for example, TLR9/GAPDH $\times 10^{6}$ and adiponectin/GAPDH $\times 10^{6}$, respectively).

Every biological probe was investigated in 2-3 technical replicates. According to MIQE guidelines, technical replicates with a standard deviation of more than 0.3 difference in quantification cycle $\left(\mathrm{C}_{\mathrm{q}}\right)$ were excluded from analysis. All oligonucleotides used were purchased from Metabion (Martinsried, Germany).
Quantification of adipokine and cytokine concentrations in 3T3-L1 and primary adipocyte culture supernatants, of adiponectin serum levels in murine samples and of resistin serum levels in human samples

Murine adiponectin, $\mathrm{MCP} 1$ and resistin and human resistin protein concentrations were measured in duplicates by ELISA techniques (murine MCP-1: Mouse MCP-1 ELISA MAX Standard from BioLegend, Koblenz, Germany; all other assay kits: DuoSet ELISA development systems from R\&D Systems, Wiesbaden, Germany) and are expressed as means \pm s.E.M. Detection ranges of the applied ELISA kits were $31.3-2000 \mathrm{pg} / \mathrm{mL}$ (for murine adiponectin), $62.5-4000 \mathrm{pg} / \mathrm{mL}$ (for murine MCP-1), $15.6-1000 \mathrm{pg} / \mathrm{mL}$ (for murine resistin) and $31.3-2000 \mathrm{pg} / \mathrm{mL}$ (for human resistin). Coefficient of variation $(\mathrm{CV})$ of values within duplicate measurements was less than $20 \%$. For 3T3-L1 and primary murine adipocyte culture supernatants, adiponectin, MCP-1 and resistin levels were normalized to total cell protein content in each well, as was quantified applying BCA Protein Assay Kit (ThermoFisher).

\section{Oil-Red 0 staining of 3T3-L1 adipocytes}

$10 \%$ formaldehyde (ROTH, Karlsruhe, Germany) in phosphate-buffered saline (PBS, Biochrom GmbH) was used to fix adipocytes. After fixation, cells were washed with 60\% isopropanol (Sigma-Aldrich $\mathrm{GmbH}$ ) and airdried. Within a 20-min incubation with Oil Red O solution (Sigma-Aldrich), adipocyte lipid vacuoles were stained red. Prior to optical microscopy, cells were washed with sterile water.

\section{Immunocytochemistry (ICC)}

3T3-L1 fibroblasts were differentiated into mature adipocytes as described previously. The shock-frozen sections were fixed with ice cold acetone (ROTH, Karlsruhe, Germany) for immunocytochemistry. Air-dried cells were incubated in PBS for rehydration. Endogenous peroxidase activity was blocked with $3 \% \mathrm{H}_{2} \mathrm{O}_{2}$ (ROTH). To avoid non-specific protein binding, cells were incubated in $10 \%$ bovine serum albumin (BSA, ROTH), $10 \%$ fetal calf serum (FCS, Sigma-Aldrich) and 10\% chicken serum (Sigma-Aldrich), followed by 3 -h incubation in a moist chamber with rabbit anti-mouse TLR9 antibody $(5 \mu \mathrm{g} / \mathrm{mL}$ in 1\% BSA; ab37154; Abcam). Cells were then stained with peroxidase-conjugated goat anti-rabbit IgG $(2.5 \mu \mathrm{g} / \mathrm{mL}$ in https://joe.bioscientifica.com

https://doi.org/10.1530/JOE-18-0326 (c) 2019 Society for Endocrinology Published by Bioscientifica Ltd. Printed in Great Britain 
1\% BSA; P0448; DAKO) for $90 \mathrm{~min}$. Color development with 3-amino-9-ethylcarbazole (AEC) substrate (Vector Laboratories, Burlingame, CA, USA) at room temperature was stopped after microscopic examination. Rabbit isotype-matched IgG sera (ab27478; Abcam) served as an isotype control. Parallel experiments without primary antibody were carried out as negative controls.

\section{Immunohistochemistry (IHC)}

Formalin-fixed murine and human adipose tissue was embedded in paraffin. Paraffin was removed with xylene (ROTH) and rehydrated by consecutive washing steps with 100, 96 and 70\% ethanol (ROTH), aqua dest. and PBS. Endogenous peroxidase activity was blocked with 3\% $\mathrm{H}_{2} \mathrm{O}_{2}$. Tissue samples were incubated for $60 \mathrm{~min}$ in citrate buffer at $60^{\circ} \mathrm{C}$. Non-specific binding sites were blocked with 5\% BSA for $60 \mathrm{~min}$ in a humid chamber followed by an overnight incubation with rabbit anti-mouse/human TLR9 antibody (10 $\mu \mathrm{g} / \mathrm{mL}$ in 1\% BSA; ab37154; Abcam). Tissues were then stained with peroxidase-conjugated goat anti-rabbit IgG $(2.5 \mu \mathrm{g} / \mathrm{mL}$ in 1\% BSA; DAKO P0448) for $90 \mathrm{~min}$. Color development with AEC substrate (Vector Laboratories) at room temperature was stopped after microscopic examination. Rabbit isotype-matched IgG sera (ab27478; Abcam) served as an isotype control. Parallel experiments without primary antibody were carried out as negative controls.

\section{Animals}

C57BL/6 WT mice ( $n=16$; 11-12 months old, 24-28g, TaconicArtemis, Cologne, Germany) having been bred under standard conditions and fed a chow diet ad libitum were killed for organ and tissue resection. Gonadal and subcutaneous adipose tissue specimens were resected and immediately used to prepare adipocyte and SVC isolation on ice, as described earlier. Separate adipose tissue specimens were shock-frosted in liquid nitrogen for analysis of mRNA expression, as described earlier. Formalin-fixed gonadal (intra-abdominal) adipose tissue specimen from C57BL/6 WT mice ( $n=3$; male, 26 weeks old, 27-28 g) were used for immunohistochemical staining of TLR9. These mice had been bred under standard conditions and fed a chow diet ad libitum until killing for organ and tissue resection.

Balb/c Tlr9wt/wt (Charles River, Sulzfeld, Germany) vs Tlr9-deficient (Tlr9tm1Aki) mice $(n=11$ per group; female, 20-22 g) were killed, and serum was harvested, and gonadal and subcutaneous adipose tissue specimen were harvested. Adiponectin serum levels were measured by ELISA as described earlier. TLR9 mRNA expression levels in adipose tissue specimen of Tlr9wt/wt mice were analyzed by reverse transcription and real-time PCR (RT-PCR) as described earlier. Both Tlr9wt/wt mice and Tlr9-deficient (Tlr9tm1Aki) mice were a kind gift from Dr F Obermeier (Regensburg, Germany) and Dr Shizuo Akira (Osaka, Japan). As published previously, mice were back-crossed through at least seven generations to Balb/c genetic background before being used in experiments, and age-matched littermates were used as controls in the experiments (Hofmann et al. 2014, Karrasch et al. 2015).

Additional C57BL/6 WT ( $n=6$, female; 10 weeks) and Tlr9-deficient mice ( $n=6$, female, 23 weeks; Tlr9tm1Aki (Hemmi et al. 2000), C57BL/6 genetic background) having been bred under standard conditions and fed a chow diet ad libitum were killed for adipose tissue resection for primary murine pre-adipocyte isolation. For logistical reasons, these additional mice were not littermate controls; however, we found similar elevations of basal resistin and MCP1 secretion as opposed to reduced adiponectin secretion in Tlr9-deficient as compared to Tlr9wt/wt mice indicating a pro-inflammatory phenotype in adipocytes isolated from Tlr9-deficient mice as was shown in serum of Tlr9-deficient as compared to Tlr9wt/wt-mice in littermate controls earlier. Obtained gonadal and subcutaneous adipose tissue specimens were kept on ice prior to tissue digestion and pre-adipocyte isolation, as described above.

Animal breeding and tissue resections were performed at the University of Giessen and the University of Regensburg, Germany. All animal studies were approved by the local Institutional Animal Care and Use Committee (IACUC/Tierversuchskommission) of the University of Giessen and the University of Regensburg, respectively (local government agencies Regierungspraesidien Giessen and Regensburg).

\section{Patients and study cohort}

Human visceral and subcutaneous adipose tissue samples were obtained from 21 female patients (mean age: $38.2 \pm 2.5$ years (range: $20-57$ years); mean BMI: $52.0 \pm 1.1 \mathrm{~kg} / \mathrm{m}^{2}$ (range: $44.8-63.6 \mathrm{~kg} / \mathrm{m}^{2}$ )) undergoing bariatric surgery and were analyzed for TLR9 and adipokine mRNA expression. Clinical and experimental work on this study cohort was done by the ROBS 
(Research and Registry in Obesity and Bariatric Surgery) study group at the Giessen University Hospital, Germany (see 'Acknowledgements') on the basis of informed patient consent and approval of the local ethical committee.

\section{Statistical analysis}

Unless indicated otherwise, data are given as mean values \pm standard error of the mean (S.E.M.). For calculating mean values \pm standard error of the mean ( \pm s.E.M.) or \pm standard deviation ( \pm S.D.), a statistical software package (SPSS 22.0) was used. Outliers higher/lower than twice the amount of the standard deviation from the mean were excluded from analysis. Mean values were compared by the non-parametric Mann-Whitney $U$ test for two independent samples and the Kruskal-Wallis $H$ test for $k$ independent samples. Correlation analysis was done by using the Spearman-Rho test for linear variables. For correction for potential confounding parameters, partial correlation analysis was applied. A $P$ value below 0.05 (two-tailed) was considered as statistically significant.

\section{Results}

\section{TLR9 gene expression is induced during adipocyte differentiation and TLR9 protein is expressed in murine gonadal and human visceral adipocytes}

TLR9 mRNA expression was not detectable in preadipocytes (0 days); however, we found a stepwise and significant increase during differentiation into mature adipocytes (day 3 through day 9) with a maximum at day 9 (fully differentiated phenotype) (Fig. 1A). Immunocytochemical analyses demonstrated a significant induction of TLR9 protein expression during differentiation, which was found predominantly within the cytoplasm of mature adipocytes (Fig. 1B). Moreover, immunohistochemical analyses confirmed a significant TLR9 protein expression in both murine gonadal and human visceral adipose tissue adipocytes, albeit slightly less intense in the latter (Fig. 1C and D).

We next investigated TLR9 mRNA expression in adipocytes isolated from murine subcutaneous and gonadal adipose tissues as compared to the stromavascular cell fraction of these tissues. While the stromavascular cell fraction expectedly demonstrated a strong TLR9 expression signal, isolated adipocytes themselves also exhibited a significant TLR9 expression (Fig. 1E). There seemed to be a tendency towards increased TLR9 expression in gonadal over subcutaneous adipocytes, although this did not reach statistical significance ( $P=0.056$, Fig. 1E). In stroma-vascular cells, TLR9 expression was significantly increased in subcutaneous over gonadal adipose tissue $(P=0.021$; Fig. $1 \mathrm{E})$. Overall, these data implicate TLR9 as physiologically relevant molecule in mature adipocytes in mice and humans.

\section{Adipocyte lipid accumulation is dependent on intact TLR9 expression}

Since TLR9 is induced during 3T3-L1 adipocyte differentiation (Fig. 1A and B), we next asked if adipocyte differentiation reciprocally depends on TLR9 expression. Thus, 3T3-L1 pre-adipocytes were repeatedly treated (at day $0,3,6,8$ for $3 \mathrm{~h}$ each) with TLR9 siRNA compared to control siRNA during hormonally induced adipocyte differentiation. Remarkably, TLR9-siRNA treatment significantly inhibited intracellular lipid droplet formation in differentiating adipocytes as a hallmark of adipocyte differentiation compared to control-treatment as assessed by microscopic imaging (Fig. 2A) as well as Oil-red-O staining of intracellular lipid vacuoles (Fig. 2B). Adiponectin mRNA expression levels as a classical and late marker of adipocyte differentiation were significantly reduced in TLR9-siRNA-treated as compared to controltreated cells $(1369.53 \pm 120.76$ vs $2020.5 \pm 273.03$ relative to $\mathrm{GAPDH} \times 10^{6}, P=0.026$; Fig. 2C). Of note, healthy Tlr9-/- mice exhibited significantly reduced adiponectin serum levels as compared to healthy Tlr9wt/wt control mice $(8.19 \pm 0.27 \mu \mathrm{g} / \mathrm{mL}$ vs $10.89 \pm 0.26 \mu \mathrm{g} / \mathrm{mL}, P=0.008$; Fig. 2D). These data argue for a significant role of TLR9 in the regulation of adipocyte lipid accumulation and adiponectin expression and secretion.

\section{TLR9 ligands (CPG-ODNs) inhibit resistin secretion in mature 3T3-L1 adipocytes}

Since TLR9 is induced during 3T3-L1 adipocyte differentiation (Fig. 1A and B) and can be detected in mature human and murine adipocytes (Fig. 1C, D and E), we aimed to investigate whether classical TLR9 signaling is active in mature adipocytes. TLR9 is a pattern recognition receptor (PRR), whose physiological ligands comprise free bacterial non-methylated DNA containing so-called 'CpG motifs' (CpGoligodeoxynucleotides, ODNs) (Wagner 2001). Three different classes of CpG-ODNs have been characterized, each with different stimulatory activity on TLR9 (class A, B and C) (Krieg 2006, Kumagai et al. 2008, 
A

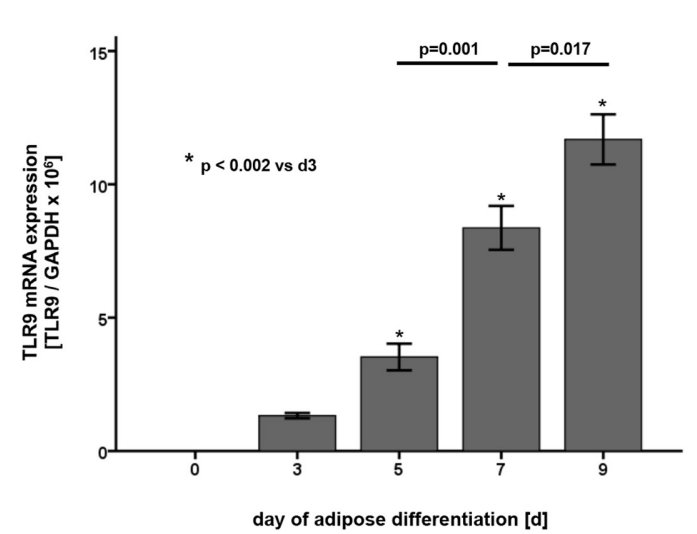

C

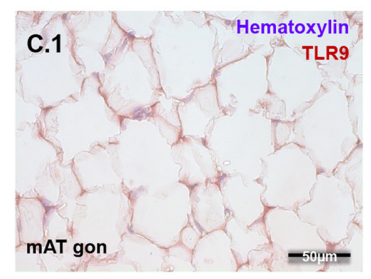

D
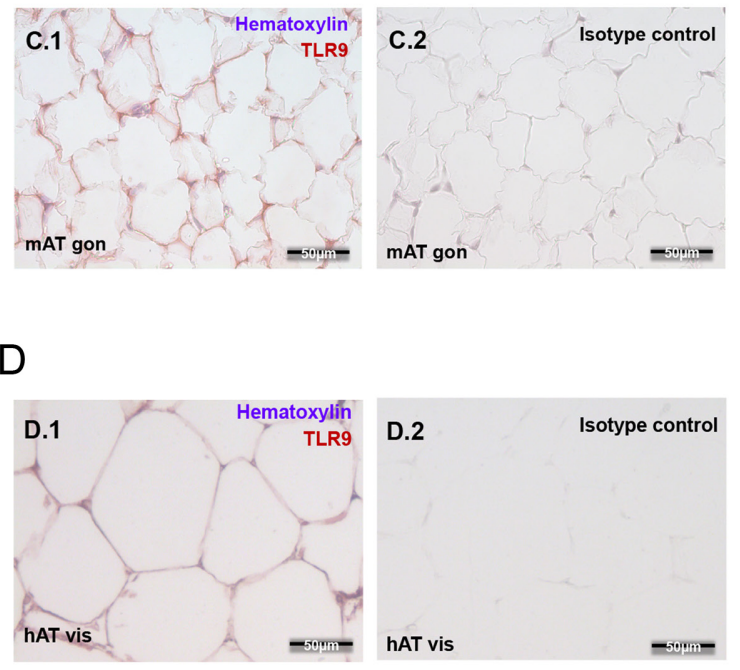

B

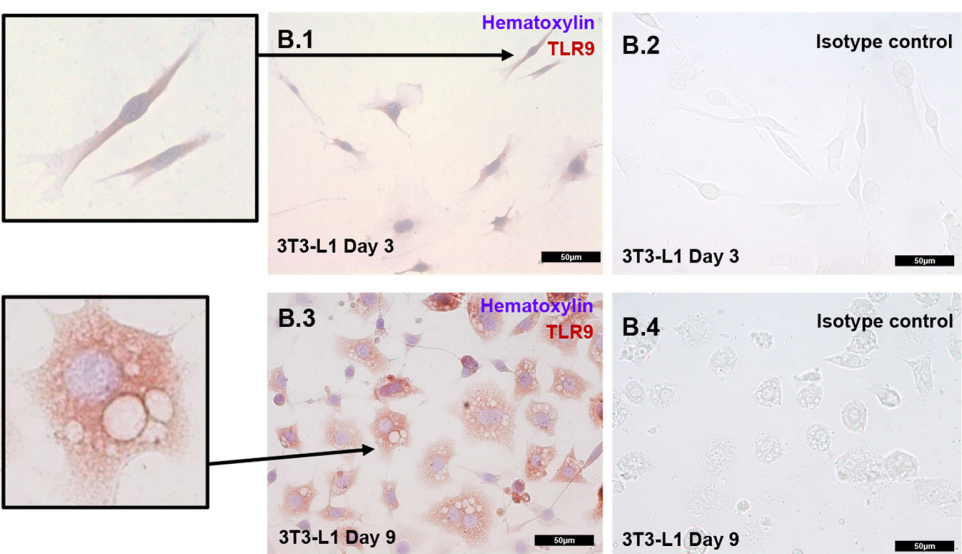

E

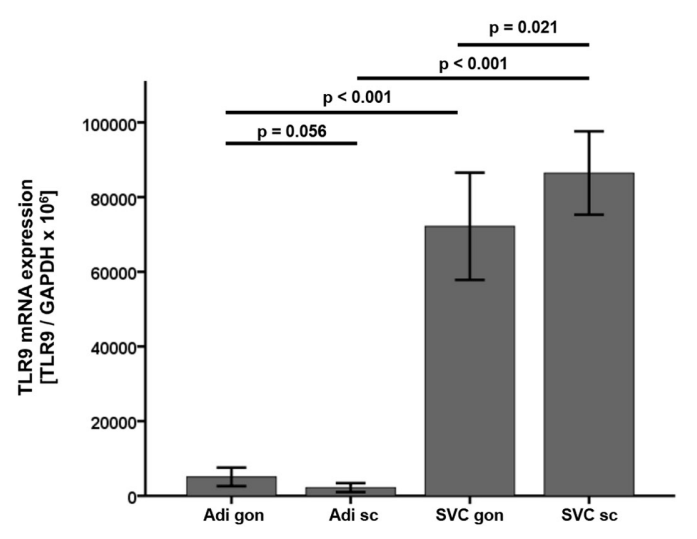

Figure 1

TIr9 gene expression is induced during adipocyte differentiation, and TLR9 protein is strongly expressed in murine gonadal and human visceral adipocytes. (A) Adipocyte differentiation was hormonally induced in murine 3T3-L1 pre-adipocytes in vitro. At the indicated time points, cells were lysed, mRNA was prepared from $n=17$ wells each and reverse transcribed, and TLR9 mRNA in relation to GAPDH mRNA $\times 10^{6}$ was analyzed by real-time PCR. TLR9 mRNA expression was not detectable in pre-adipocytes (d0); however, we found a stepwise and significant increase during differentiation into mature adipocytes ( $\mathrm{d} 3$ through $\mathrm{d} 9$ ) with a maximum at day 9 (fully differentiated phenotype). The error bars indicate $\pm 1 \times$ standard error of the mean (S.E.M.). (B) 3T3-L1 fibroblasts were differentiated into mature adipocytes and immunocytochemistry (ICC) for TLR9 protein was prepared on day 3 (B.1 and B.2) vs day 9 (B.3 and B.4) of differentiation. ICC demonstrated a significant induction of TLR9 protein expression during differentiation (d9, B.3), which was found predominantly within the cytoplasm of mature adipocytes (B.3). Representative images are shown. (C and D) Murine gonadal (mAT gon) (C) and human visceral (hAT vis) (D) adipose tissue was analysed for the expression of TLR9 protein by immunohistochemistry (IHC). IHC demonstrated a significant TLR9 expression in both murine gonadal and human visceral adipose tissue adipocytes, albeit slightly less intense in the latter. Representative images are shown. (E) Gonadal (gon) vs subcutaneous (sc) adipose tissue was harvested from $n=16$ male C57BL/ 6 mice and the adipocyte (Adi) vs the stroma-vascular cell (SVC) fraction was prepared. Cells were lysed, mRNA was prepared and reverse transcribed, and TLR9 mRNA in relation to GAPDH mRNA $\times 10^{6}$ was analyzed by real-time PCR. While the stroma-vascular cell fraction expectedly demonstrated a strong TLR9 expression signal, isolated adipocytes themselves also exhibited a lower but significant TLR9 expression. The error bars indicate $\pm 1 \times$ standard error of the mean (S.E.M.).

Furi et al. 2013). Thus, we stimulated mature 3T3-L1 adipocytes with these three classes of ODNs vs control ODNs (exhibiting a similar structure while missing the typical non-methylated CpG-motifs; $20 \mu \mathrm{g} / \mathrm{mL}$ ). As a read-out, we concentrated on the typical adipokines resistin and adiponectin, which were measured in cell culture supernatants of the adipocytes.

(c) 2019 Society for Endocrinology Published by Bioscientifica Ltd. Printed in Great Britain

\section{Class A ODN}

Remarkably, treatment with increasing doses of class A ODN (ODN 1585; 1, 5, 20 $\mu \mathrm{g} / \mathrm{mL}$ ) demonstrated a significant and dose-dependent inhibition of resistin protein secretion $(5.8,27.3$ and $74.1 \%$ reduction, respectively; $P=0.002$ vs control for 5 and $20 \mu \mathrm{g} / \mathrm{mL}$ ODN 
A
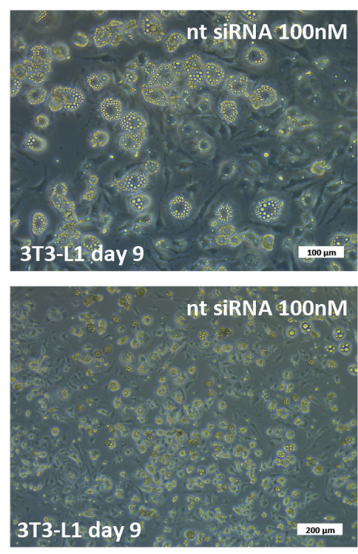
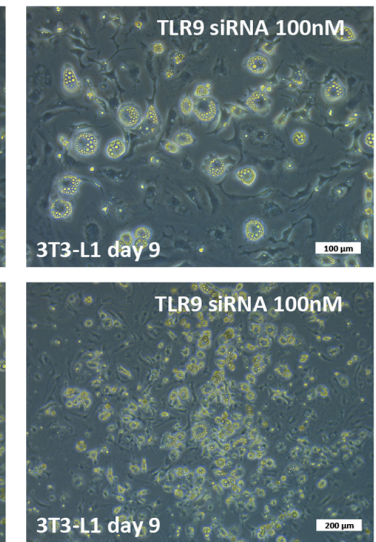

B
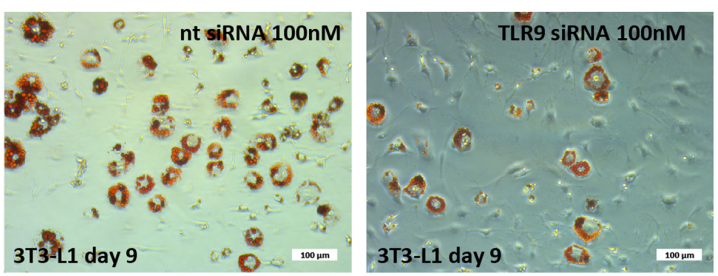

373t 1 ay
C

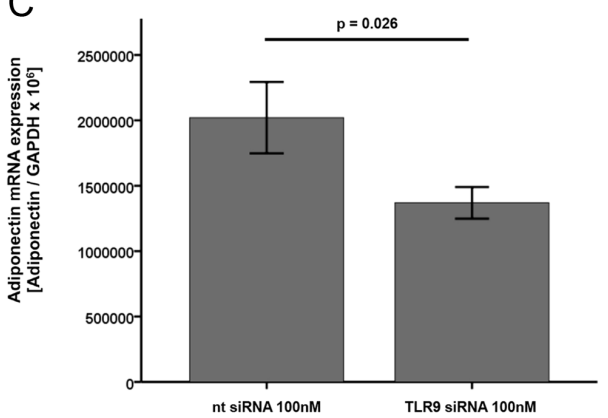




\section{Class C ODN}

Class C ODN effects on adipocyte resistin secretion were comparable to class A ODN, although slightly less effective, while class C ODN did not impact on adiponectin at all (Fig. 3M: 43.5 and $61.2 \%$ reduction of resistin with increasing ODN doses, $P=0.002$ vs control; Fig. 3Q: 46.4 and $73.9 \%$ reduction of resistin, $P=0.002$ vs LPS treatment alone).

Table 1 summarizes the effects of class A, class B and class C ODNs on mature 3T3-L1 adipocytes under basal conditions and upon LPS stimulation. ODN treatment generally inhibited resistin secretion, while there might be a weak suppression of adiponectin secretion under inflammatory conditions by class A and class B ODN. Since resistin is regarded as a key pro-inflammatoiry adipokine in diabetes mellitus and metabolic syndrome (Abate et al. 2014), these data imply anti-inflammatory effects of TLR9 signaling in mature 3T3-L1 adipocytes in vitro, with class A ODN having the strongest effect. ODN effects on resistin were preserved in the presence of LPS.

\section{TLR9 ligands (ODNs) inhibit MCP1, GLUT1 and GLUT4 mRNA accumulation in mature 3T3-L1 adipocytes}

Since pro-inflammatory changes in visceral adipose tissue have been associated with obesity and insulin resistance (Gregor \& Hotamisligil 2011), anti-inflammatory effects of TLR9 ligands might directly modulate these pathophysiological sequelae of low-grade adipose tissue inflammation. To evaluate the impact of CpG-ODNs on markers of inflammation and glucose metabolism in adipocytes on a cellular level, we next evaluated the effect of these ligands on monocyte chemoattractant protein 1 (MCP1, CCL2), interleukin 6 (IL-6), glucose transporter 1 (GLUT1, SLC2A1) and glucose transporter 4

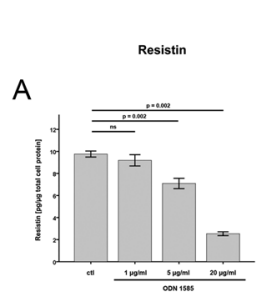

B

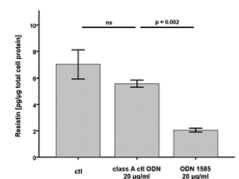

E

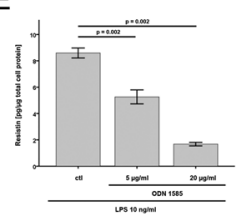

C

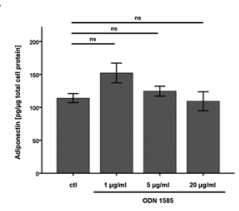

D
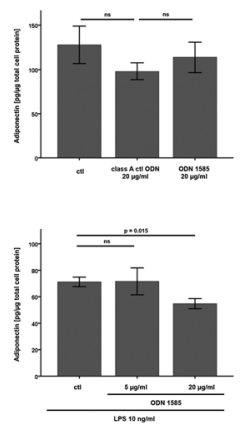

G

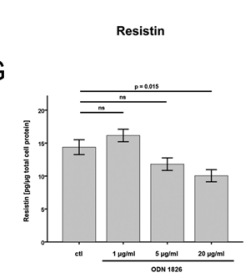

$\mathrm{H}$

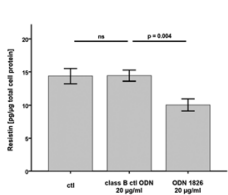

$\mathrm{K}$

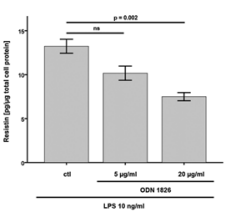

ODN 1826

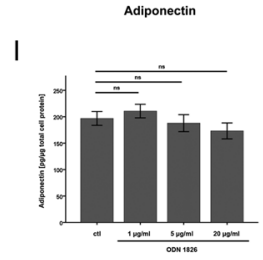

J

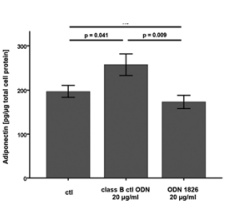

L

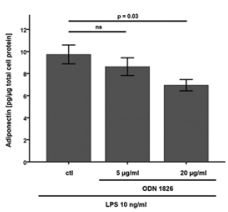

M

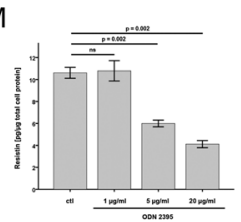

N

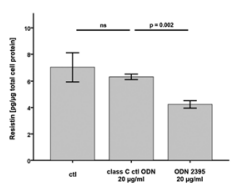

Q

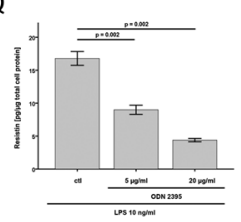

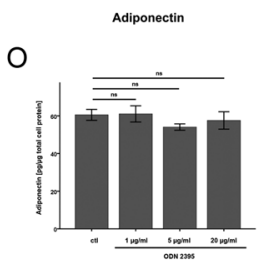

$\mathrm{P}$

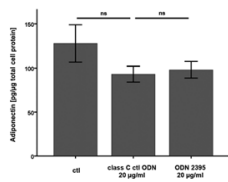

$\mathrm{R}$

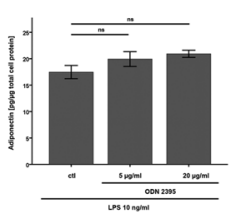

Figure 3

TLR9 ligand class A CpG-ODN (ODN 1585) inhibits resistin secretion, TLR9 ligand class B CpG-ODN (ODN 1826) inhibits resistin and partly adiponectin secretion and TLR9 ligand class C CPG-ODN (ODN 2395) inhibits resistin secretion into cell culture supernatants in mature 3 T3-L1 adipocytes in vitro. Mature 3T3-L1 adipocytes were stimulated with increasing doses of class A ODN (ODN 1585; 1, 5, 20 Hg/mL) vs class A control ODN (class A ctl ODN; $20 \mu \mathrm{g} / \mathrm{mL}$; exhibiting a similar structure while missing the typical non-methylated CpG-motifs) vs solvent control (ctl). Resistin and adiponectin levels in cell culture supernatants from $n=6$ wells each were assessed by ELISA measurements and were normalized to total cell protein content in each well. The error bars indicate $\pm 1 \times$ standard error of the mean (S.E.M.). (A) Class A ODN induced a significant and dose-dependent inhibition of resistin protein secretion into cell culture supernatants. (B) Treatment with class A control ODN did not have an effect on resistin secretion. (C) Treatment with increasing doses of class A ODN did not impact on basal adiponectin protein secretion into cell culture supernatants. (D) Treatment with class A control ODN did not have an effect on basal adiponectin secretion. (E) Pre-incubation (1 h) of mature 3T3-L1 adipocytes with class A ODN (ODN 1585; 5, 20 $\mu$ g/mL) followed by stimulation by LPS (10 ng/mL) led to a significant and dose-dependent inhibition of resistin protein secretion into cell culture supernatants as well. (F) Pre-incubation (1 h) of mature 3T3-L1 adipocytes with higher doses of class A ODN (ODN 1585; $20 \mu \mathrm{g} / \mathrm{mL}$ ) followed by stimulation with LPS (10 ng/mL) led to a significant inhibition of adiponectin protein secretion into cell culture supernatants. (G, H, I, J, K and L) Similar experiments as reported for class $A$ ODN were performed using class B ODN. Class B ODN had a similar impact on resistin and adiponectin secretion compared to class A ODN, albeit with an overall lesser effect size. (M, N, O, P, Q and R) Similar experiments as reported for class A ODN were performed using class C ODN. Class C ODN effects on adipocyte resistin secretion were comparable to class A ODN, although slightly less effective, while class C ODN did not impact on adiponectin at all. (light gray bars, resistin; dark gray bars, adiponectin; ns, not significant). 
A

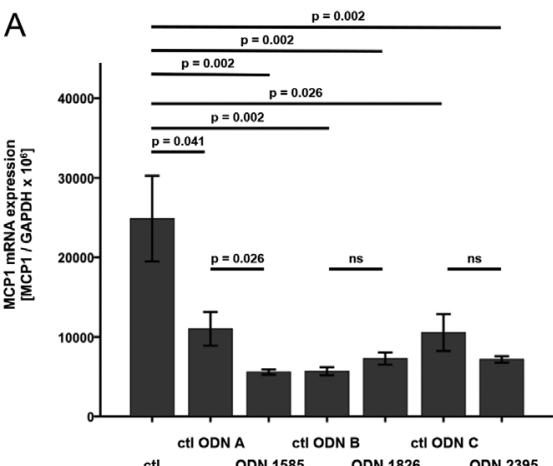

B

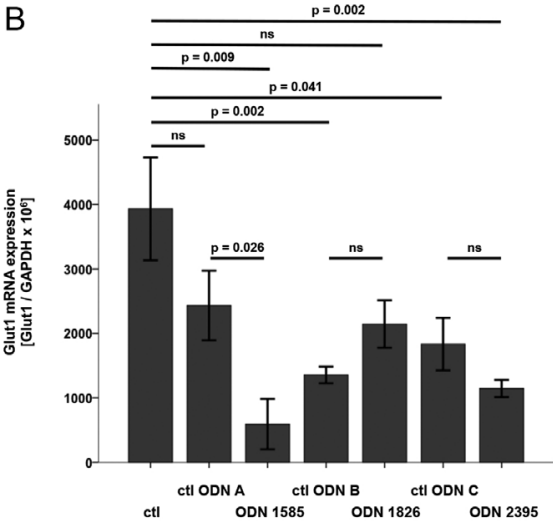

C

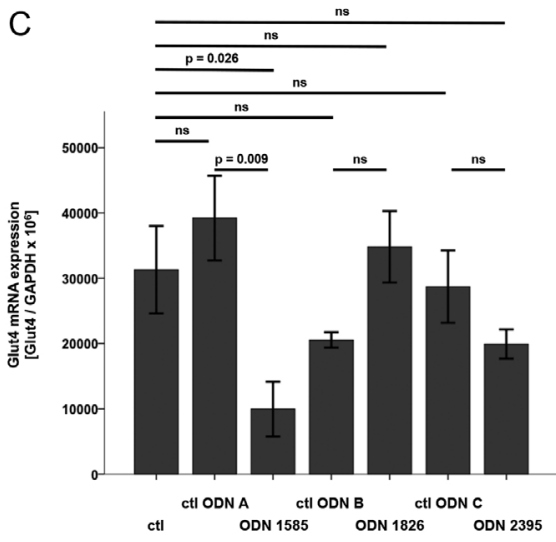

\section{Figure 4}

TLR9 ligands (ODNs) inhibit MCP1, GLUT1 and GLUT4 mRNA accumulation in mature 3T3-L1 adipocytes in vitro. Mature 3T3-L1 adipocytes were stimulated with class A ODN (ODN 1585; $20 \mu \mathrm{g} / \mathrm{mL}$ ), class B ODN (ODN 1826; $20 \mu \mathrm{g} / \mathrm{mL}$ ) and class C ODN (ODN 2395; $20 \mu \mathrm{g} / \mathrm{mL}$ ) vs the respective control ODNs $(20 \mu \mathrm{g} / \mathrm{mL}$; exhibiting a similar structure while missing the typical nonmethylated CpG-motifs) vs solvent control (ctl). After isolation of mRNA, mRNA accumulation of murine MCP-1, GLUT1 and GLUT4 was quantified by reverse transcription and real-time PCR (RT-PCR) of the corresponding CDNA (A) Control ODN A, B and C significantly reduced basal MCP1 mRNA accumulation as compared to solvent control. Class A ODN reduced MCP1 expression even further compared to control ODN A, which was not observed with ODN B and C. (B, C) Class A ODN profoundly reduced both GLUT1 and GLUT4 mRNA accumulation as compared to class A control ODN treated cells. Class B and class C ODN did not have this effect. While class A, $B$ and $C$ control ODN themselves reduced GLUT1 mRNA accumulation compared to solvent treated controls, they did not impact on GLUT4 mRNA accumulation at all.

(C) 2019 Society for Endocrinology Published by Bioscientifica Ltd. Printed in Great Britain
(GLUT4, SLC2A4) mRNA accumulation in 3T3-L1 adipocytes in vitro.

Interestingly, class A ODN (ODN 1585; 20 $\mu \mathrm{g} / \mathrm{mL}$ ) significantly inhibited MCP1 mRNA accumulation as compared to class A control ODN (Fig. 4A). We did not observe this effect with class $\mathrm{B}$ and class $\mathrm{C}$ ODN compared to the respective ODN controls. Remarkably, class $\mathrm{A}, \mathrm{B}$ and $\mathrm{C}$ control ODNs themselves - representing free DNA, but missing the bacterial-specific 'CpG motifs' (Wagner 2001) - significantly reduced MCP1 mRNA accumulation vs solvent treated controls, indicating additional effects of free DNA independent of the 'CpG motifs' (Fig. 4A). ODN treatment did not impact on IL-6 mRNA accumulation (data not shown).

Importantly, class A ODN profoundly reduced both GLUT1 and GLUT4 mRNA accumulation as compared to class A control ODN-treated cells (Fig. 4B and C). Class B and class $C$ ODN did not have this effect. While class A, $B$ and $C$ control ODNs themselves reduced GLUT1 mRNA accumulation compared to solvent-treated controls (Fig. 4B), they did not have an impact on GLUT4 mRNA accumulation at all (Fig. 4C).

In summary, these data indicate that TLR9 signaling induced by class A ODN inhibits pro-inflammatory MCP1 gene expression in 3T3-L1 adipocytes in vitro; however, cell-free DNA itself has a significant inhibitory effect. Remarkably, class A ODN profoundly reduces GLUT1 and GLUT4 gene expression, potentially leading to a reduced glucose uptake by adipocytes. Cell-free oligodeoxynucleotides themselves inhibit GLUT1, but not GLUT4 gene expression in adipocytes.

Primary murine TIr9-/- as compared to Tlr9wt/wt adipocytes exhibit increased resistin and MCP1 secretion and reduced adiponectin secretion into cell culture supernatants, while TLR9 ligands (ODNs) show differential effects in TIr9-/- vs TIr9wt/wt primary murine adipocytes

Since CpG-ODNs reduced resistin secretion into cell culture supernatants in 3T3-L1 adipocytes, indicating an anti-inflammatory effect (Fig. 3), we next investigated basal adipokine secretion in primary murine adipocytes isolated from Tlr9-/- vs Tlr9wt/wt mice. Remarkably, we found that basal resistin and MCP1 secretion was significantly increased in Tlr9-/- vs Tlr9wt/wt primary murine adipocytes, while adiponectin secretion was significantly reduced (Fig. 5A). Thus, overall, Tlr9-/adipocytes exhibit an inflammatory phenotype as compared to Tlr9wt/wt adipocytes. As control, induction 
A

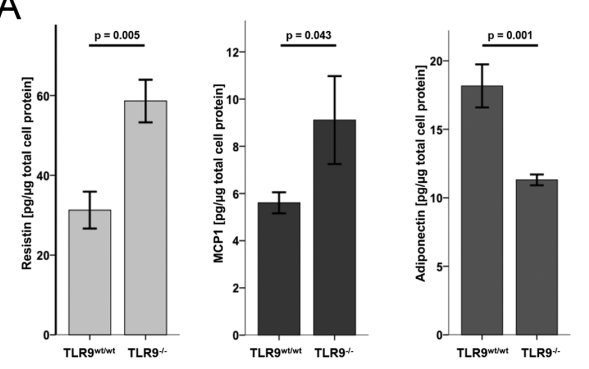

C

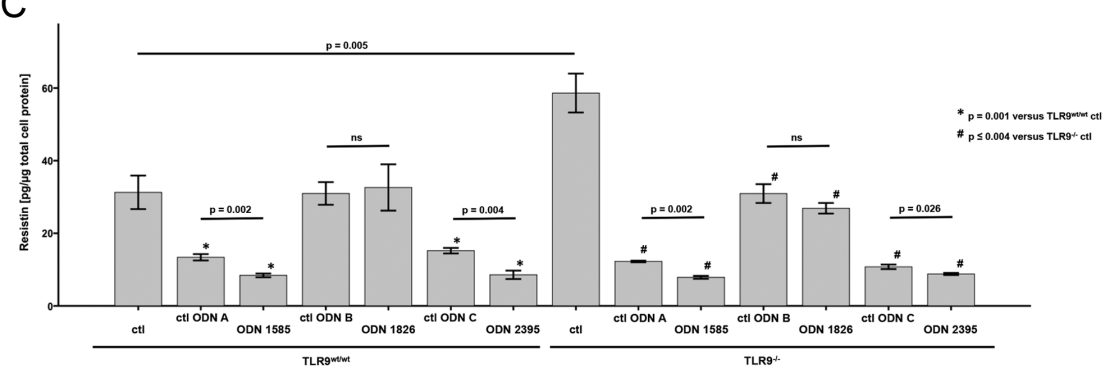

D

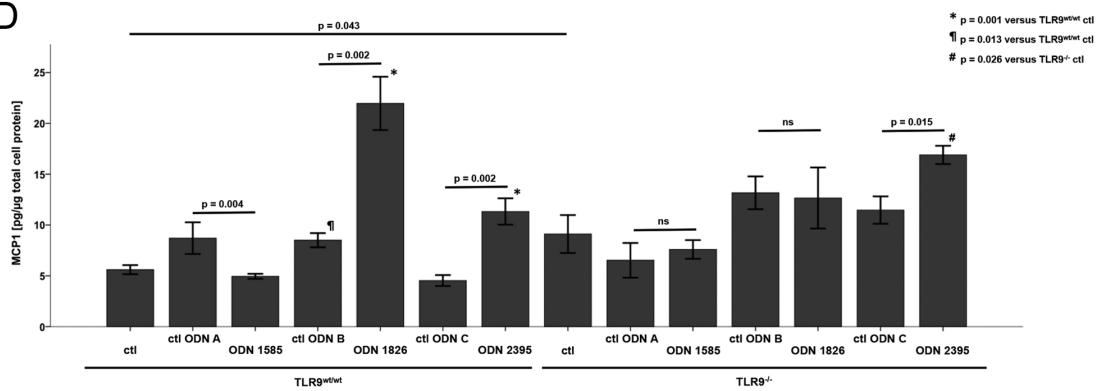

E

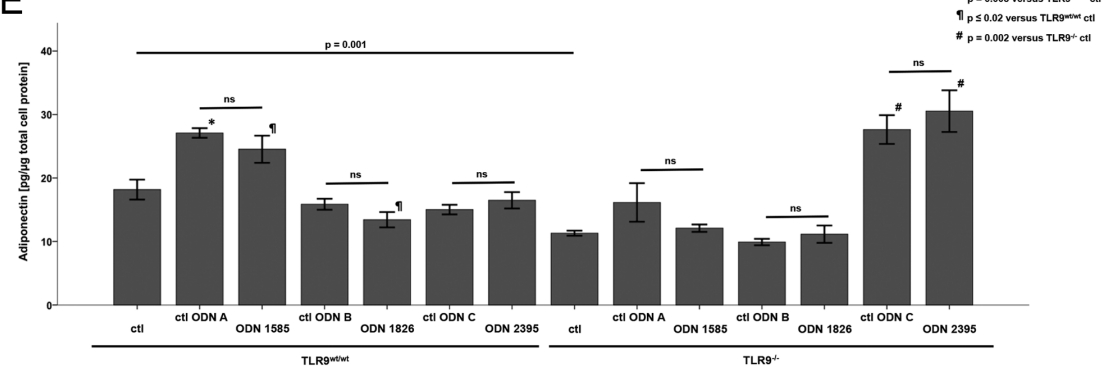

B

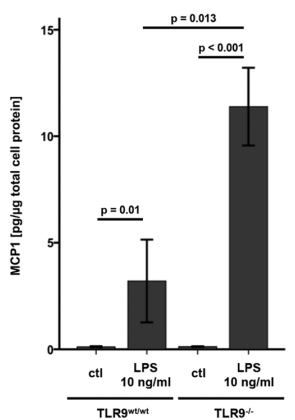

\section{Figure 5}

Primary murine TIr9-/- as compared to TIr9wt/wt adipocytes exhibit increased resistin and MCP1 secretion and reduced adiponectin secretion into cell culture supernatants, while TLR9 ligands (ODNs) show differential effects in TIr9-/- vs TIrgwt/ wt primary murine adipocytes. Primary preadipocytes were isolated from fresh subcutaneous ( $A ; C, D$ and $E$ ) and gonadal (B) adipose tissue from TIrgwt/wt. as compared to TIr9-I--mice as described in the Methods section. Adipocyte differentiation was hormonally induced in vitro, and mature adipocytes at day 11 of differentiation were stimulated with class A ODN (ODN 1585; $20 \mu \mathrm{g} / \mathrm{mL}$ ), class B ODN (ODN 1826; $20 \mu \mathrm{g} / \mathrm{mL}$ ) and class C ODN (ODN 2395; $20 \mu \mathrm{g} / \mathrm{mL}$ ) vs the respective control ODNs $(20 \mu \mathrm{g} / \mathrm{mL}$; exhibiting a similar structure while missing the typical non-methylated CpG-motifs) vs solvent control (ctl). Resistin, MCP1 and adiponectin levels in cell culture supernatants from $n=6$ wells each were assessed by ELISA measurements and were normalized to total cell protein content in each well. The error bars indicate $\pm 1 \times$ standard error of the mean (S.E.M.). (A) Tlrgwt/wt-adipocytes demonstrate significantly increased basal resistin and MCP1 secretion and significantly reduced basal adiponectin secretion as compared to TIr9-/-adipocytes. (B) TLR4-dependent induction of MCP1-secretion stimulated by LPS-treatment $(10 \mathrm{ng} / \mathrm{mL})$ was intact in both T/r9wt/wt. and TIr9-/--adipocytes, however, TIr9-/--adipocytes exhibited a significantly stronger induction of MCP1 by LPS as compared to TIrgwt/wt-adipocytes. (C, D and E) Treatment of TIrgwt/wt- vs TIr9-/-adipocytes with class $A, B$ and $C O D N$ vs control ODN had differential effects on resistin, MCP1 and adiponectin secretion into cell culture supernatants (compare text). of TLR9-independent pro-inflammatory signalling via LPS stimulation $(10 \mathrm{ng} / \mathrm{mL})$ revealed an expected, strong induction of MCP1 secretion in both Tlr9wt/wt and Tlr9-/adipocytes, indicating that other immune responses were intact (Fig. 5B).

We next asked how the TLR9 genotype impacted on the effects of different ODN classes on adipokine secretion. In Tlr9wt/wt primary murine adipocytes, class A ODN (ODN 1585; 20 $\mu \mathrm{g} / \mathrm{mL}$ ) significantly inhibited resistin and MCP1 secretion as compared to class A control ODN (Fig. 5C, D and E). Resistin, but not MCP1 secretion, was inhibited in Tlr9-/- adipocytes. No effect of class A ODN compared to control ODN was observed on adiponectin secretion. Remarkably, class A control ODN itself profoundly reduced resistin secretion in both Tlr9wt/wt and Tlr9-/- adipocytes, increased adiponectin secretion in Tlr9wt/wt but not Tlr9-/- adipocytes and did not impact on MCP1 secretion in neither Tlr9wt/wt nor Tlr9-/- adipocytes, (Fig. 5C, D and E). Thus, overall, class A ODN exhibited an anti-inflammatory effect, which was in part dependent on intact TLR9 (MCP1 inhibition).

Class B ODN (ODN 1826; 20 $\mu \mathrm{g} / \mathrm{mL})$ did not impact on resistin secretion and slightly reduced adiponectin secretion in Tlr9wt/wt adipocytes as compared to class B control ODN (Fig. 5C, D and E). Remarkably, class B ODN profoundly increased MCP1 secretion in Tlr9wt/wt 
Table 1 Summary of class A, class B and class C ODN effects on the secretion of the adipokines resistin and adiponectin into cell culture supernatants in mature 3T3-L1 adipocytes under basal and inflammatory conditions (co-stimulation with LPS 10 ng/mL).

\begin{tabular}{|c|c|c|c|c|c|}
\hline & & \multicolumn{2}{|c|}{ Basal } & \multicolumn{2}{|c|}{ Inflammatory conditions (LPS $10 \mathrm{ng} / \mathrm{mL}$ ) } \\
\hline & & & ODN conc. & & \\
\hline & & & $1 \mu \mathrm{g} / \mathrm{mL}$ & & ODN conc. \\
\hline & & & $5 \mu \mathrm{g} / \mathrm{mL}$ & & $5 \mu \mathrm{g} / \mathrm{mL}$ \\
\hline & & Overall effect & $20 \mu \mathrm{g} / \mathrm{mL}$ & Overall effect & $20 \mu \mathrm{g} / \mathrm{mL}$ \\
\hline \multirow[t]{9}{*}{ Resistin } & Class A ODN (ODN 1585) & $\downarrow \downarrow \downarrow$ & $-6 \%$ & $\downarrow \downarrow \downarrow$ & \\
\hline & & & $-27 \%$ & & $-39 \%$ \\
\hline & & & $-74 \%$ & & $-80 \%$ \\
\hline & Class B ODN (ODN 1826) & $\downarrow$ & - & $\downarrow$ & \\
\hline & & & - & & - \\
\hline & & & $-30 \%$ & & $-43 \%$ \\
\hline & Class C ODN (ODN 2395) & $\downarrow \downarrow$ & - & $\downarrow \downarrow$ & \\
\hline & & & $-43 \%$ & & $-44 \%$ \\
\hline & & & $-61 \%$ & & $-61 \%$ \\
\hline \multirow[t]{7}{*}{ Adiponectin } & Class A ODN (ODN 1585) & $\leftrightarrow$ & & $\downarrow$ & \\
\hline & & & & & - \\
\hline & & & & & $-23 \%$ \\
\hline & Class B ODN (ODN 1826) & $\leftrightarrow$ & & $\downarrow$ & \\
\hline & & & & & - \\
\hline & & & & & $-29 \%$ \\
\hline & Class C ODN (ODN 2395) & $\leftrightarrow$ & & $\leftrightarrow$ & \\
\hline
\end{tabular}

$\downarrow$, moderate suppression; $\downarrow \downarrow$, strong suppression; $\downarrow \downarrow \downarrow$, very strong suppression; $\leftrightarrow$, no change; LPS, lipopolysaccharide; ODN, CpG oligodeoxynucleotide; ODN conc., ODN concentration.

adipocytes as compared to control ODN. Class B ODN as compared to control ODN did not impact on resistin, MCP1 or adiponectin secretion in Tlr9-/- adipocytes. Class B control ODN itself did not influence resistin and adiponectin and merely slightly increased MCP1 secretion in Tlr9wt/wt adipocytes. In Tlr9-/- adipocytes, class B control ODN left MCP1 and adiponectin secretion unchanged, while significantly inhibiting resistin secretion (Fig. 5C, $\mathrm{D}$ and E). Overall, these data point toward a potential TLR9-dependent, pro-inflammatory effect of class B ODN (MCP1 induction).

In Tlr9wt/wt adipocytes, class C ODN (ODN 2395, $20 \mu \mathrm{g} / \mathrm{mL}$ ) significantly inhibited resistin secretion and increased MCP1 secretion vs class C control ODN, while leaving adiponectin secretion unchanged (Fig. 5C, D and E). Similar effects were observed in Tlr9-/- adipocytes, albeit to a lesser extent. Remarkably, class C control ODN itself profoundly inhibited resistin secretion and did not impact on MCP1 secretion in both Tlr9-/- and Tlr9wt/wt adipocytes. In Tlr9-/- adipocytes, class C control ODN significantly increased adiponectin secretion, which was not observed in Tlr9wt/wt adipocytes (Fig. 5C, D and E). Thus, overall, class C ODN exhibited a mixed pro- and anti-inflammatory effect, which was largely independent of intact TLR9 signaling.
In summary, these observations in primary murine adipocytes point towards an overall anti-inflammatory net effect of TLR9 signaling (Fig. 5A). However, different classes of ODNs mediate differential effects, and additional receptors have to be postulated to mediate the observed effects that are independent of TLR9.

\section{TLR9 expression is significantly increased in visceral over subcutaneous adipose tissue depots in non- diabetic obese patients undergoing bariatric surgery}

TLR9 has recently been postulated to play a role in obesity and insulin resistance (Hong et al. 2015, Ghosh et al. 2016, Nishimoto et al. 2016). Insulin resistance has been associated to inflammatory changes in particular within the visceral adipose tissue compartment (Hardy et al. 2012, Ghosh et al. 2016, Revelo et al. 2016). Thus, we asked if different fat depots exhibit distinct TLR9 expression profiles in vivo. We found no difference in TLR9 mRNA expression levels in murine subcutaneous vs gonadal adipose tissue depots in healthy Balb/c mice (Fig. 6A; $n=11$ mice; female; 20-22 g). Remarkably, however, 21 female obese patients undergoing bariatric surgery not suffering from diabetes mellitus (mean age: $38.2 \pm 2.5$ years (range: 20-57 years); mean BMI: $52.0 \pm 1.1 \mathrm{~kg} / \mathrm{m}^{2}$ 

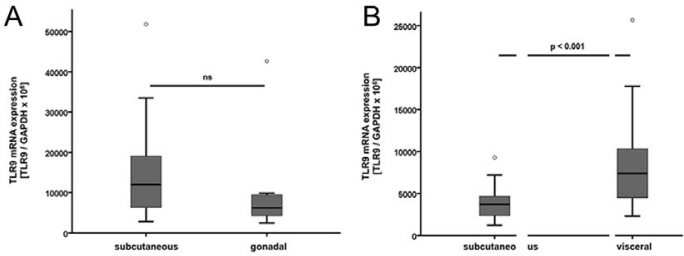

C
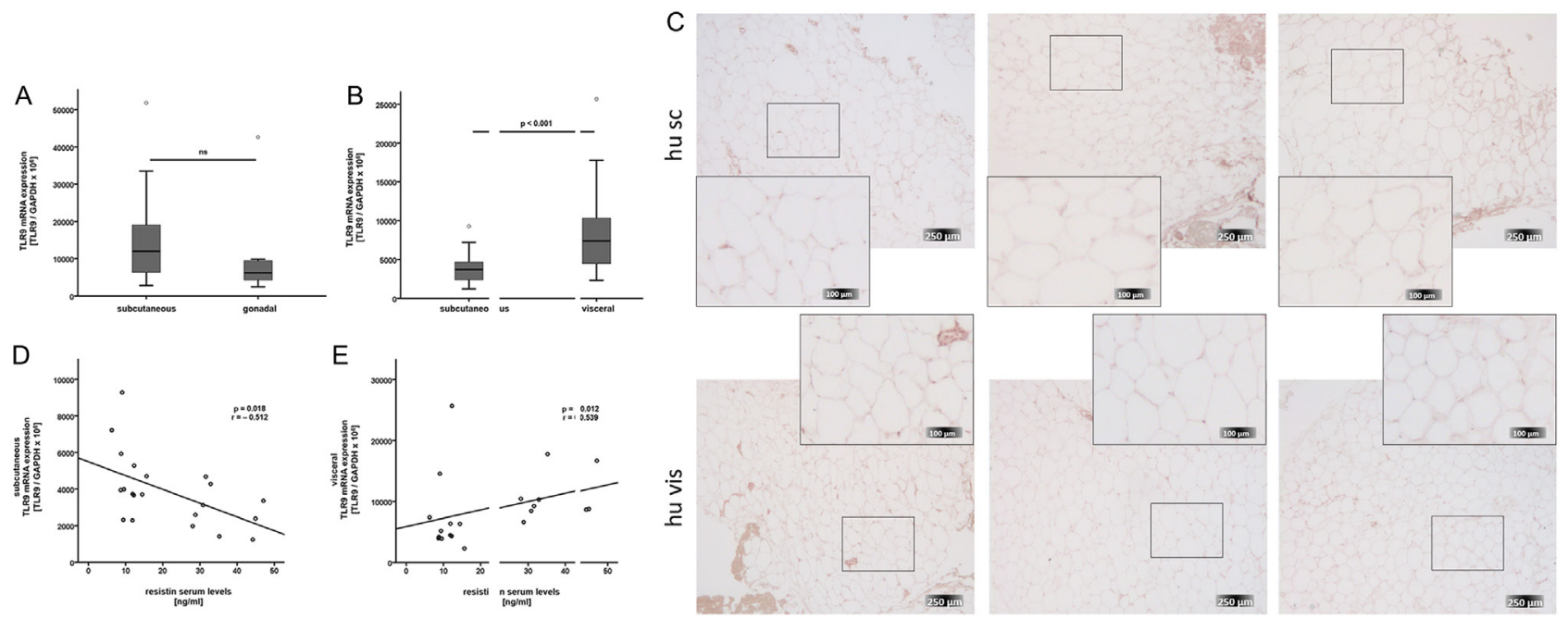

\section{Figure 6}

TLR9 expression is significantly increased in visceral over subcutaneous adipose tissue depots in female non-diabetic obese patients undergoing bariatric surgery and correlates with systemic resistin levels in a compartment-specific manner. (A) Healthy female wild-type Balb/c mice ( $n=11$; weighing $20-22$ g) were sacrificed, and adipose tissue specimen were collected from subcutaneous vs gonadal adipose tissue depots. Cells were lysed, mRNA was prepared and reverse transcribed, and TLR9 mRNA in relation to GAPDH mRNA $\times 10^{6}$ was analyzed by real-time PCR. There were no differences in TLR9 mRNA expression levels in murine subcutaneous over gonadal adipose tissue depots. Data are given as box plots; the boundary of the box closest to zero indicates the 25 th percentile, a line within the box marks the median, and the boundary of the box farthest from zero indicates the 75th percentile. Whiskers above and below the box indicate the highest/lowest values that are within 1.5 times the interquartile range (Tukey's whiskers). (B) Human visceral and subcutaneous adipose tissue samples were obtained from 21 female patients not suffering from diabetes mellitus (mean age: $38.2 \pm 2.5$ years (range: 20-57 years); mean BMl: $52.0 \pm 1.1$ kg/m² (range: $\left.44.8-63.6 \mathrm{~kg} / \mathrm{m}^{2}\right)$ ) undergoing bariatric surgery and were analyzed for TLR9 mRNA expression. TLR9 mRNA expression (as assessed relative to GAPDH mRNA expression $\times 10^{6}$ ) was significantly increased in visceral adipose tissue depots as compared to subcutaneous adipose tissue depots. Data are given as box plots as described in (A). (C) Immunohistochemical analyses in three matched human subcutaneous and visceral adipose tissue specimen indicated that there is significant inter-individual variability in TLR9 protein accumulation between patients. ( $D$ and E) Human visceral and subcutaneous adipose tissue samples were obtained from 21 female patients undergoing bariatric surgery and were analyzed for TLR9 mRNA expression as described in (B). Serum samples from these 21 patients were collected before the bariatric operation, and resistin serum levels were measured by ELISA. Resistin serum levels were significantly correlated to adipose tissue TLR9 mRNA expression levels in a compartment-specific manner, demonstrating a negative correlation to subcutaneous adipose tissue TLR9 expression (D) and a positive correlation to visceral adipose tissue TLR9 expression (E).

(range: $\left.44.8-63.6 \mathrm{~kg} / \mathrm{m}^{2}\right)$ ) showed significantly increased TLR9 mRNA expression (as assessed relative to GAPDH mRNA expression $\left.\times 10^{6}\right)$ in visceral adipose tissue depots as compared to subcutaneous adipose tissue depots $(P<0.001$, Fig. 6B). Of note, additional immunohistochemical analyses in matched human subcutaneous and visceral adipose tissue specimen indicated that there is significant inter-individual variability in TLR9 protein accumulation as assessed by immunohistochemistry between patients (Fig. 6C).

\section{TLR9 mRNA expression correlates with systemic resistin levels in female obese patients undergoing bariatric surgery in a compartment-specific manner}

We next asked if TLR9 expression in various adipose tissue depots impacts on systemic adipokine serum levels in obese patients in vivo. Thus, both visceral and subcutaneous adipose tissue samples were retrieved from 21 female obese patients undergoing bariatric surgery (mean age and mean BMI given above). To exclude confounders, patients suffering from diabetes mellitus as well as patients using anti-diabetic medication (e.g. metformin, DPP4-inhibitors) were excluded from our analysis.

Remarkably, we found a significant negative correlation between TLR9 mRNA expression in subcutaneous adipose tissue and resistin serum levels $(P=0.018 ; \quad r=-0.512$; Fig. 6D). Interestingly, as opposed to subcutaneous adipose tissue, TLR9 mRNA expression in visceral adipose tissue demonstrated a significant positive correlation to resistin serum levels $(P=0.012 ; r=0.539$; Fig. $6 \mathrm{E})$.

\section{Discussion}

Originally described and functionally characterized in B-lymphocytes, Toll-like receptor 9 (TLR9) signaling has recently been demonstrated in additional cell types 
such as intestinal epithelial cells (Lee et al. 2006). The classical ligand of TLR9 is bacterial, non-methylated DNA, containing so-called 'CpG motifs' (CpG deoxynucleotides, ODNs) (Wagner 2001). However, recent studies have demonstrated that eukaryotic, cell-free DNA (cfDNA) functions as a physiological TLR9 ligand as well (Kumagai et al. 2008, Welner et al. 2008, Guillerey et al. 2012). Consequently, TLR9 plays an important role both during pathogen-induced systemic immune reactions as well as during autoimmune inflammation like for example lupus erythematosus.

In B-lymphocytes, virus-induced TLR9 signaling leads to anti-viral pro-inflammatory cytokine production like for example TNF $\alpha$, IL-6 and IL-12 (Guillerey et al. 2012). On the other hand, TLR9 exerts both pro-inflammatory as well as anti-inflammatory effects in the context of autoimmune diseases (Banchereau \& Pascual 2006, Kumagai et al. 2008, Nickerson et al. 2010, Jackson et al. 2014, Bossaller et al. 2016). On intestinal epithelial cells, TLR9 has been demonstrated to play an important homeostatic role protecting mice from experimental colitis (Lee et al. 2006). And in conventional dendritic cells (cDCs), TLR9 activation induces anti-inflammatory interleukin-10 (IL-10) secretion attenuating inflammatory responses and liver ischemia/reperfusion injury in mice (Bamboat et al. 2010).

Recent studies have hinted at an important role of TLR9 signaling in obesity, glucose intolerance and insulin resistance. In this context, TLR9 signaling in the visceral adipose tissue depot in particular seems to play a key role (Hong et al. 2015, Ghosh et al. 2016, Nishimoto et al. 2016, Revelo et al. 2016). However, the extent in which individual cell types within the complex adipose tissue microenvironment contribute to the observed effects remains elusive (Apostolopoulos et al. 2016). Thus, we asked if TLR9 signaling plays a role in adipocytes themselves - given their recently appreciated active role in local and systemic anti-viral and anti-bacterial immune reactions (Nakatsuji et al. 2013, Yu et al. 2014, Zhang et al. 2015)

Our data demonstrate that TLR9 mRNA is significantly induced during differentiation of 3T3-L1 adipocytes in vitro, leading to constantly increasing mRNA levels (Fig. 1A). Immunohistochemistry proved that TLR9 protein was induced during differentiation as well (Fig. 1B). TLR9 protein was located mainly within the cytoplasm of adipocytes (Fig. 1B), matching the subcellular localization that has been described for B-lymphocytes within the endosomal compartment (Wagner 2001). Remarkably, both the expression of PPAR $\gamma$ and of TLR9 are dependent

C 2019 Society for Endocrinology Published by Bioscientifica Ltd. Printed in Great Britain on the terminal adipogenic transcription factor $\mathrm{C} / \mathrm{EBP} \alpha$. This possible interrelation on the level of transcriptional regulation might be responsible for increased TLR9 expression during late adipocyte differentiation (Takeshita et al. 2004, Cristancho \& Lazar 2011, Garcia-Alonso \& Claria 2014).

Treatment of pre-adipocytes during differentiation with siRNA against TLR9 impaired adipocytic intracellular fat accumulation as well as adiponectin mRNA expression (Fig. 2A, B and C), possibly indicating a defect in adipocytic differentiation. In line with these data, Revelo et al. recently observed significantly decreased visceral adipose tissue fat pads in Tlr9-/- as compared to Tlr9wt/wt mice under conditions of a high-fat diet (Revelo et al. 2016). Of note, early adipocyte differentiation (pre-adipocyte commitment) is mediated via MAPKp38-dependent C/EBPS activation (Cho et al. 2015). Since TLR9 signals through MAPKp38 as well, this might be a possible link between adipocyte differentiation and TLR9 signaling. Future molecular and mechanistic studies will have to dissect this interplay in more detail.

Interestingly, we found that treatment of mature 3T3-L1 adipocytes with classical TLR9 ligands CpG-ODN led to a dose-dependent, significant reduction of basal resistin secretion into cell culture supernatants. These effects were demonstrated at different levels for all classes (class A, B and C) of CpG-ODNs and were not found with control ODNs that are missing the 'CpG motifs' responsible for classical TLR9 signaling induction. Similar observations were made in adipocytes stimulated by LPS $(10 \mathrm{ng} / \mathrm{mL})$, mimicking the pro-inflammatory environment in (visceral) adipose tissue of obese patients (Weisberg et al. 2003, Apostolopoulos et al. 2016). CpG-ODN treatment did not impact on basal adiponectin secretion into cell culture supernatants in resting 3T3-L1 adipocytes and only led to a slight reduction of adiponectin secretion in adipocytes pre-treated with LPS (Fig. 3 and Table 1). Since the adipokine resistin has been associated with pro-inflammatory effects (Bokarewa et al. 2005, Hutcheson 2015), especially in metabolic syndrome, diabetes mellitus and cardiovascular disease (Abate et al. 2014), while adiponectin has been associated with antiinflammatory effects (Tilg \& Moschen 2006, Ohashi et al. 2010), these observations imply an anti-inflammatory effect of adipocytic TLR9 signaling in 3T3-L1 adipocytes, that is preserved upon LPS stimulation.

We observed that MCP1 expression is decreased in 3T3-L1 adipocytes treated with class A CpG-ODN as compared to control ODN A (Fig. 4A). Class B and C ODN did not exhibit a CpG-specific effect; however, all ODN 
treatment significantly inhibited MCP1 expression. No effects were observed on basal IL-6 expression in 3T3-L1 adipocytes. These data support an anti-inflammatory role of oligodeoxynucleotide treatment in adipocytes as well. Remarkably, class A ODN treatment significantly reduced GLUT1 and GLUT 4 glucose transporter expression (Fig. 4B and C). These observations argue for a possible TLR9-dependent impact of class A CpG-ODNs on glucose uptake of adipocytes, potentially reprogramming the adipocytic cellular metabolism. Of note, downregulation of GLUT4 (and possibly GLUT1) transporters on cell membranes would render adipocytes insulin resistant and thus would provide a direct link to the pathophysiology of obesity and (visceral) adipose tissue pro-inflammatory transformation, where hypoxia has recently been shown to play an important role in these processes (VarelaGuruceaga et al. 2018). Future experiments evaluating the impact of class A CpG-ODN on GLUT1 and GLUT4 mRNA expression vs intra-cellular transporter translocation under high vs low glucose in high vs low insulin conditions as well as lipolysis assays will elaborate on these observations.

To further define the TLR9 ligand receptor relationship in adipocytes, we performed additional experiments in primary murine adipocytes isolated from Tlr9wt/wt_ vs Tlr9-/--mice. Remarkably, basal MCP1 and resistin secretion were markedly increased while adiponectin secretion was significantly reduced in Tlr9-/- as compared to Tlr9wt/wt primary adipocytes (Fig. 5A), arguing for an overall anti-inflammatory effect of intact adipocytic TLR9 signaling.

Surprisingly, stimulation of primary Tlr9wt/wt and Tlr9-/- adipocytes with class A, B and C ODNs vs control ODNs revealed that the marked inhibitory effect of ODN treatment on resistin secretion was largely independent of the TLR9 genotype. In fact, resistin inhibition was also independent of the classical 'CpG motifs' (Fig. 5C, D and $\mathrm{E}$ ). Thus, additional receptors have to be postulated mediating the effects of oligodeoxynucleotide treatment in adipocytes. For example, Revelo et al. recently demonstrated that both the TLR9- and TLR7-nucleic acid-targeting pathways are responsible for sensing cellfree DNA (cfDNA) and extracellular traps (ETs) in human and murine obesity (Revelo et al. 2016). Further potential candidates are the Toll-like receptors 3 and 8 (TLR3, TLR8) (Takeuchi \& Akira 2010). Future research using the respective specific knock-out models will be able to address this question.

In Tlr9wt/wt adipocytes, we observed a profound increase in MCP1 secretion following stimulation with class B
ODN, while class A ODN suppressed MCP1 secretion, which was not seen in Tlr9-/- adipocytes (Fig. 5D). Thus, ODN class A- and class B-mediated effects on adipocytic MCP1 secretion are TLR9 specific. These results complement recent data reporting that ODN 1826 (ODN class B)-dependent MCP1-expression in mouse peritoneal macrophages is TLR9 dependent (Nishimoto et al. 2016); however, the authors of this study did not report on the effects of other ODN classes. ODN class C increased MCP1 secretion in both Tlr9wt/wt and Tlr9-/- adipocytes (Fig. 5D). With the exception of a non-CpG-motif-dependent, slight increase in Tlr9wt/wt adipocytes, and a strong increase in Tlr9-/- adipocytes, adiponectin secretion remained largely independent of ODN treatment, as had been observed in 3T3-L1 adipocytes (Figs 3 and 5E and Table 1).

In summary, experiments in primary murineadipocytes confirmed an overall pro-inflammatory phenotype in Tlr9-/- as opposed to Tlr9wt/wt adipocytes (Figs 2D and 5A, B). However, our detailed analysis of different classes of ODNs both containing and missing 'CpG motifs' stresses the fact that different ODNs elicit differential responses in adipocytes, which are merely in part TLR9- and/or specific CpG-motif dependent. It has recently been demonstrated that TLR-dependent priming of BMDM is a prerequisite for an inflammatory effect of lcSFA, which - after TLRdependent metabolic cellular reprogramming - lead to pro-inflammatory changes via inducing endoplasmatic reticulum (ER) stress (Lancaster et al. 2018). Remarkably, a high-fat diet induces a significant translocation of bacterial DNA over the intestinal mucosal barrier, which can be found at increased levels both in the systemic circulation as well as in visceral adipose tissue depots in mice after 1 week of high-fat diet (Amar et al. 2011). Of note, functional adipocytic NF- $\mathrm{BB}$ signal transduction is a prerequisite for healthy adipose tissue remodeling, thus further proving its important role in obesity (Wernstedt Asterholm et al. 2014). Thus, adipocytic TLR9-dependent signaling - especially within the visceral adipose tissue depot - can be postulated to serve important homeostatic functions (Kwon et al. 2014, Karrasch \& Schaffler 2016), especially in the context of over-nutrition and obesity. Recent studies demonstrated that cell-free DNA as well as so-called extracellular traps (consisting of nucleic acids and anti-microbial peptides derived from macrophages and neutrophil granulocytes) are increased in obesity and activate macrophages as well as dendritic cells in a TLR9- and TLR7-dependent manner independent of specific CpG-oligodeoxynucleotides (Nishimoto et al. 2016, Revelo et al. 2016). Mechanisms like for example reprogramming of the adipocytic cellular metabolism 
and the induction of ER-stress by oligodeoxynucleotides might be responsible for at least part of the observations we made in adipocytes, and future work will have to elaborate on these results.

Our data complement recent studies by Revelo et al. and Ghosh et al. who found that TLR9 expression and activation in particular in visceral adipose tissue led to proinflammatory changes during obesity and were associated with insulin resistance (Ghosh et al. 2016, Revelo et al. 2016). In this context, it is remarkable that we found increased levels of TLR9 in visceral fat stores of obese patients that did not (yet) suffer from diabetes mellitus, potentially indicating an early event in the development of insulin resistance and diabetes mellitus. On the other hand, Tlr9-/- mice were protected from steatohepatitis and insulin resistance in mouse models of hepatic injury via reduced hepatic stellate cell IL-1 $\beta$ production (Miura et al. 2010). Thus, the physiological outcome of TLR9dependent signaling seems to depend on the individual cell types expressing TLR9. Future experiments will have to dissect the individual impact of TLR9 signaling in the different cell types within fat depots during metabolically relevant adipose tissue inflammation in the context of obesity, insulin resistance and diabetes mellitus in more detail (adipocytes vs the stroma-vascular cell fraction). Additionally, further studies will have to include normalweight subjects and other disease states in these analyses.

Overall, multiplestudies found that pattern recognition receptor (PRR)-induced signaling serves protective roles in obesity-associated metabolic inflammation. For example, a high-fat diet upregulated NOD2 in hepatocytes and adipocytes in mice, while Nod2-/--mice exhibited increased adipose tissue inflammation and exacerbated insulin resistance after feeding on a high-fat diet (Denou et al. 2015). Injecting the bacterial cell wall component muramyl dipeptide (MDP) - that requires NOD2 sensing into obese mice lowered adipose tissue inflammation and improved glucose tolerance without causing weight loss (Cavallari et al. 2017). And Tlr5-/--mice display increased adipose tissue inflammation, obesity and loss of glycemic control mimicking insulin resistance as compared to WT mice (Vijay-Kumar et al. 2010). At least in Nod2-l-and $\operatorname{Tr} 5^{-/-}$-mice, these observations were associated to changes in the intestinal microbiome. On the other hand, pro-inflammatory, inflammasome-mediated caspase-1 activation directs adipocytes toward a more insulinresistant phenotype, and caspase-1-1- as well as Nlrp3-/mice display overall higher fat oxidation rates and their adipocytes are more insulin sensitive as compared to
WT controls (Stienstra et al. 2010). Interestingly, type 2 diabetic patients treated with IL1-receptor antagonists display improved glycemic control and beta-cell function (Larsen et al. 2007). If similar mechanisms of metabolic reprogramming including alterations in fat oxidation rates, in inflammasome activity and changes in the intestinal microbiome can be observed in Tlr9-/--mice as compared to Tlr9wt/wt controls remains to be investigated.

Interestingly, different adipose tissue depots exhibit differential TLR9 mRNA expression levels: In female obese patients undergoing bariatric surgery, we found increased TLR9 gene expression levels in visceral over subcutaneous adipose tissue (Fig. 6B). At the same time, TLR9 mRNA expression correlates with systemic resistin levels in these patients in a compartment-specific manner: We found a positive correlation of (pro-inflammatory) systemic resistin levels with visceral adipose tissue TLR9 mRNA expression. However, subcutaneous adipose tissue TLR9 mRNA expression was negatively correlated to resistin serum levels (Fig. 6D and E).

It has to be noted that these observations included different cell types within the respective adipose tissue depots; thus, most of the TLR9 expression and presumably of the resistin secretion found in these studies can be assumed to stem from the stroma-vascular cell fraction, not the adipocytes themselves (Fig. 1E). Additionally, immunohistochemical analyses in matched human subcutaneous and visceral adipose tissue specimen indicated that - albeit overall TLR9 gene expression is significantly increased in visceral as compared to subcutaneous adipose tissue - there seems to be significant inter-individual variability in TLR9 protein accumulation. Of note, recent reports indicated functionally different compartments within the subcutaneous adipose tissue, which are separated by Scarpia's fascia: The superficial adipose tissue layer had significantly higher numbers of tissue-infiltrating macrophages as compared to the deep adipose tissue layer (Cappellano et al. 2018). In this context, our study concentrated on the superficial adipose tissue layer within the subcutaneous adipose tissue. Future studies should elaborate on these observations and should also include longitudinal analyses evaluating changes in TLR9 expression levels in different adipose tissue compartments before and after bariatric surgery.

\section{Declaration of interest}

The authors declare that there is no conflict of interest that could be perceived as prejudicing the impartiality of the research reported. (c) 2019 Society for Endocrinology Published by Bioscientifica Ltd. Printed in Great Britain 


\section{Funding}

This work has been supported by a grant of the German Research Foundation to T Karrasch (DFG Sachbeihilfe; DFG KA 1846/4-1).

\section{Acknowledgements}

This work has been supported by a grant of the German Research Foundation to T Karrasch (DFG Sachbeihilfe; DFG KA 1846/4-1). The generous and expert support of Dr F Obermeier (Regensburg, Germany) regarding the generation of serum and adipose tissue samples from Tlrgwt/ wt and T/r9-/- mice is greatly appreciated. The generous gift of TIrgwt/wt_ and TIr9-/--mice by Prof. Stefan Bauer and Dr Philipp Yu, both Institute of Immunology, Philipps University of Marburg, Germany, is sincerely appreciated. The laboratory work of K Hardes and L Philippus on ELISA and on adipocyte cell cultures is highly appreciated. The collaborative work of the ROBS (Research and Registry in Obesity and Bariatric Surgery) study group at Giessen University Hospital, Germany, on the cohort of patients undergoing bariatric surgery (E Arapogianni, J Albrecht, S Akinci, J Brock, I Busse, A Häusler, A Hauenschild, M Koukou, J Kruse, W Padberg, J Schlegel, A Schmid, B Schmidt, A Schultz) is highly appreciated.

\section{References}

Abate N, Sallam HS, Rizzo M, Nikolic D, Obradovic M, Bjelogrlic P \& Isenovic ER 2014 Resistin: an inflammatory cytokine. Role in cardiovascular diseases, diabetes and the metabolic syndrome. Current Pharmaceutical Design 20 4961-4969. (https://doi.org/10.2174/138161 2819666131206103102)

Abdullah A, Wolfe R, Stoelwinder JU, de Courten M, Stevenson C, Walls HL \& Peeters A 2011 The number of years lived with obesity and the risk of all-cause and cause-specific mortality. International Journal of Epidemiology 40 985-996. (https://doi.org/10.1093/ije/dyr018)

Amar J, Chabo C, Waget A, Klopp P, Vachoux C, Bermudez-Humaran LG, Smirnova N, Berge M, Sulpice T, Lahtinen S, et al. 2011 Intestinal mucosal adherence and translocation of commensal bacteria at the early onset of type 2 diabetes: molecular mechanisms and probiotic treatment. EMBO Molecular Medicine 3 559-572. (https://doi. org/10.1002/emmm.201100159)

Apostolopoulos V, de Courten MP, Stojanovska L, Blatch GL, Tangalakis K $\&$ de Courten B 2016 The complex immunological and inflammatory network of adipose tissue in obesity. Molecular Nutrition and Food Research 60 43-57. (https://doi.org/10.1002/mnfr.201500272)

Bachmeier M \& Loffler G 1994 Adipogenic activities in commercial preparations of fetuin. Hormone and Metabolic Research 26 92-96. (https://doi.org/10.1055/s-2007-1000780)

Bae J, Ricciardi CJ, Esposito D, Komarnytsky S, Hu P, Curry BJ, Brown PL, Gao Z, Biggerstaff JP, Chen J, et al. 2014 Activation of pattern recognition receptors in brown adipocytes induces inflammation and suppresses uncoupling protein 1 expression and mitochondrial respiration. American Journal of Physiology-Cell Physiology $\mathbf{3 0 6}$ C918-C930. (https://doi.org/10.1152/ajpcell.00249.2013)

Bamboat ZM, Ocuin LM, Balachandran VP, Obaid H, Plitas G \& DeMatteo RP 2010 Conventional DCs reduce liver ischemia/ reperfusion injury in mice via IL-10 secretion. Journal of Clinical Investigation 120 559-569. (https://doi.org/10.1172/JCI40008)

Banchereau J \& Pascual V 2006 Type I interferon in systemic lupus erythematosus and other autoimmune diseases. Immunity $\mathbf{2 5}$ 383-392. (https://doi.org/10.1016/j.immuni.2006.08.010)

Bokarewa M, Nagaev I, Dahlberg L, Smith U \& Tarkowski A 2005 Resistin, an adipokine with potent proinflammatory properties. Journal of Immunology 174 5789-5795. (https://doi.org/10.4049/ jimmunol.174.9.5789)
Bossaller L, Christ A, Pelka K, Nundel K, Chiang PI, Pang C, Mishra N, Busto P, Bonegio RG, Schmidt RE, et al. 2016 TLR9 deficiency leads to accelerated renal disease and myeloid lineage abnormalities in pristane-induced murine lupus. Journal of Immunology 197 1044-1053. (https://doi.org/10.4049/jimmunol.1501943)

Cappellano G, Morandi EM, Rainer J, Grubwieser P, Heinz K, Wolfram D, Bernhard D, Lobenwein S, Pierer G \& Ploner C 2018 Human macrophages preferentially infiltrate the superficial adipose tissue. International Journal of Molecular Sciences 19 1404. (https://doi. org/10.3390/ijms19051404)

Caputo T, Gilardi F \& Desvergne B 2017 From chronic overnutrition to metaflammation and insulin resistance: adipose tissue and liver contributions. FEBS Letters 591 3061-3088. (https://doi. org/10.1002/1873-3468.12742)

Cavallari JF, Fullerton MD, Duggan BM, Foley KP, Denou E, Smith BK, Desjardins EM, Henriksbo BD, Kim KJ, Tuinema BR, et al. 2017 Muramyl dipeptide-based postbiotics mitigate obesity-induced insulin resistance via IRF4. Cell Metabolism 25 1063.e1063-1074.e1063. (https://doi.org/10.1016/j.cmet.2017.03.021)

Cho YL, Min JK, Roh KM, Kim WK, Han BS, Bae KH, Lee SC, Chung SJ \& Kang HJ 2015 Phosphoprotein phosphatase 1СB (РPP1CB), a novel adipogenic activator, promotes 3T3-L1 adipogenesis. Biochemical and Biophysical Research Communications 467 211-217. (https://doi. org/10.1016/j.bbrc.2015.10.004)

Cornelius P, MacDougald OA \& Lane MD 1994 Regulation of adipocyte development. Annual Review of Nutrition 14 99-129. (https://doi. org/10.1146/annurev.nu.14.070194.000531)

Cristancho AG \& Lazar MA 2011 Forming functional fat: a growing understanding of adipocyte differentiation. Nature Reviews Molecular Cell Biology 12 722-734. (https://doi.org/10.1038/nrm3198)

Denou E, Lolmede K, Garidou L, Pomie C, Chabo C, Lau TC, Fullerton MD, Nigro G, Zakaroff-Girard A, Luche E, et al. 2015 Defective NOD2 peptidoglycan sensing promotes diet-induced inflammation, dysbiosis, and insulin resistance. EMBO Molecular Medicine 7 259-274. (https://doi.org/10.15252/emmm.201404169)

Furi I, Sipos F, Germann TM, Kalmar A, Tulassay Z, Molnar B \& Muzes G 2013 Epithelial toll-like receptor 9 signaling in colorectal inflammation and cancer: clinico-pathogenic aspects. World Journal of Gastroenterology 19 4119-4126. (https://doi.org/10.3748/wjg.v19.i26.4119)

Garcia-Alonso V \& Claria J 2014 Prostaglandin E2 signals white-tobrown adipogenic differentiation. Adipocyte 3 290-296. (https://doi. org/10.4161/adip.29993)

Ghosh AR, Bhattacharya R, Bhattacharya S, Nargis T, Rahaman O, Duttagupta P, Raychaudhuri D, Chen Liu CS, Roy S, Ghosh P, et al. 2016 Adipose recruitment and activation of plasmacytoid dendritic cells fuel metaflammation. Diabetes 65 3440-3452. (https://doi. org/10.2337/db16-0331)

Grant RW \& Stephens JM 2015 Fat in flames: influence of cytokines and pattern recognition receptors on adipocyte lipolysis. American Journal of Physiology-Endocrinology and Metabolism 309 E205-E213. (https:// doi.org/10.1152/ajpendo.00053.2015)

Green H \& Kehinde O 1975 An established preadipose cell line and its differentiation in culture. II. Factors affecting the adipose conversion. Cell 5 19-27. (https://doi.org/10.1016/0092-8674(75)90087-2)

Green H \& Kehinde O 1979 Formation of normally differentiated subcutaneous fat pads by an established preadipose cell line. Journal of Cellular Physiology 101 169-171. (https://doi.org/10.1002/ jcp.1041010119)

Green H \& Meuth M 1974 An established pre-adipose cell line and its differentiation in culture. Cell 3 127-133. (https://doi. org/10.1016/0092-8674(74)90116-0)

Gregor MF \& Hotamisligil GS 2011 Inflammatory mechanisms in obesity. Annual Review of Immunology 29 415-445. (https://doi.org/10.1146/ annurev-immunol-031210-101322)

Guillerey C, Mouries J, Polo G, Doyen N, Law HK, Chan S, Kastner P, Leclerc C \& Dadaglio G 2012 Pivotal role of plasmacytoid dendritic 
cells in inflammation and NK-cell responses after TLR9 triggering in mice. Blood 120 90-99. (https://doi.org/10.1182/blood-2012-02410936)

Hardy OT, Czech MP \& Corvera S 2012 What causes the insulin resistance underlying obesity? Current Opinion in Endocrinology, Diabetes and Obesity 19 81-87. (https://doi.org/10.1097/MED.0b013e3283514e13)

Hemmi H, Takeuchi O, Kawai T, Kaisho T, Sato S, Sanjo H, Matsumoto M, Hoshino K, Wagner H, Takeda K, et al. 2000 A Toll-like receptor recognizes bacterial DNA. Nature $\mathbf{4 0 8}$ 740-745. (https://doi. org/10.1038/35047123)

Hofmann C, Dunger N, Doser K, Lippert E, Siller S, Edinger M, Falk W \& Obermeier F 2014 Physiologic TLR9-CpG-DNA interaction is essential for the homeostasis of the intestinal immune system. Inflammatory Bowel Diseases 20 136-143. (https://doi.org/10.1097/01. MIB.0000436276.19755.c1)

Hong CP, Yun CH, Lee GW, Park A, Kim YM \& Jang MH 2015 TLR9 regulates adipose tissue inflammation and obesity-related metabolic disorders. Obesity 23 2199-2206. (https://doi.org/10.1002/oby.21215)

Hutcheson J 2015 Adipokines influence the inflammatory balance in autoimmunity. Cytokine 75 272-279. (https://doi.org/10.1016/j. cyto.2015.04.004)

Jackson SW, Scharping NE, Kolhatkar NS, Khim S, Schwartz MA, Li QZ, Hudkins KL, Alpers CE, Liggitt D \& Rawlings DJ 2014 Opposing impact of B cell-intrinsic TLR7 and TLR9 signals on autoantibody repertoire and systemic inflammation. Journal of Immunology 192 4525-4532. (https://doi.org/10.4049/jimmunol.1400098)

Karrasch T \& Schaffler A 2016 Adipokines and the role of visceral adipose tissue in inflammatory bowel disease. Annals of Gastroenterology 29 1-15. (https://doi.org/10.20524/aog.2016.0077)

Karrasch T, Schmid A, Kopp A, Obermeier F, Hofmann C \& Schaffler A 2015 Impact of toll-like-receptor-9 (TLR9) deficiency on visceral adipose tissue adipokine expression during chronic DSS-induced colitis in mice. Experimental and Clinical Endocrinology and Diabetes 123 80-87. (https://doi.org/10.1055/s-0034-1398502)

Kim SJ, Choi Y, Choi YH \& Park T 2012 Obesity activates toll-like receptor-mediated proinflammatory signaling cascades in the adipose tissue of mice. Journal of Nutritional Biochemistry 23 113-122. (https:// doi.org/10.1016/j.jnutbio.2010.10.012)

Kopp A, Buechler C, Bala M, Neumeier M, Scholmerich J \& Schaffler A 2010 Toll-like receptor ligands cause proinflammatory and prodiabetic activation of adipocytes via phosphorylation of extracellular signalregulated kinase and c-Jun N-terminal kinase but not interferon regulatory factor-3. Endocrinology 151 1097-1108. (https://doi. org/10.1210/en.2009-1140)

Krieg AM 2006 Therapeutic potential of Toll-like receptor 9 activation. Nature Reviews Drug Discovery 5 471-484. (https://doi.org/10.1038/ nrd2059)

Kumagai Y, Takeuchi O \& Akira S 2008 TLR9 as a key receptor for the recognition of DNA. Advanced Drug Delivery Reviews 60 795-804. (https://doi.org/10.1016/j.addr.2007.12.004)

Kwon H, Laurent S, Tang Y, Zong H, Vemulapalli P \& Pessin JE 2014 Adipocyte-specific IKKbeta signaling suppresses adipose tissue inflammation through an IL-13-dependent paracrine feedback pathway. Cell Reports 9 1574-1583. (https://doi.org/10.1016/j. celrep.2014.10.068)

Lancaster GI, Langley KG, Berglund NA, Kammoun HL, Reibe S Estevez E, Weir J, Mellett NA, Pernes G, Conway JRW, et al. 2018 Evidence that TLR4 is not a receptor for saturated fatty acids but mediates lipid-induced inflammation by reprogramming macrophage metabolism. Cell Metabolism 27 1096.e1095-1110.e1095. (https://doi. org/10.1016/j.cmet.2018.03.014)

Larsen CM, Faulenbach M, Vaag A, Volund A, Ehses JA, Seifert B, Mandrup-Poulsen T \& Donath MY 2007 Interleukin-1-receptor antagonist in type 2 diabetes mellitus. New England Journal of Medicine 356 1517-1526. (https://doi.org/10.1056/NEJMoa065213)
Lee J, Mo JH, Katakura K, Alkalay I, Rucker AN, Liu YT, Lee HK, Shen C, Cojocaru G, Shenouda S, et al. 2006 Maintenance of colonic homeostasis by distinctive apical TLR9 signalling in intestinal epithelial cells. Nature Cell Biology 8 1327-1336. (https://doi. $\operatorname{org} / 10.1038 /$ ncb1500)

MacDougald OA \& Lane MD 1995 Transcriptional regulation of gene expression during adipocyte differentiation. Annual Review of Biochemistry 64 345-373. (https://doi.org/10.1146/annurev. bi.64.070195.002021)

Miura K, Kodama Y, Inokuchi S, Schnabl B, Aoyama T, Ohnishi H, Olefsky JM, Brenner DA \& Seki E 2010 Toll-like receptor 9 promotes steatohepatitis by induction of interleukin-1beta in mice. Gastroenterology 139 323.e327-334.e327. (https://doi.org/10.1053/j. gastro.2010.03.052)

Nakatsuji T, Chiang HI, Jiang SB, Nagarajan H, Zengler K \& Gallo RL 2013 The microbiome extends to subepidermal compartments of normal skin. Nature Communications 4 1431. (https://doi.org/10.1038/ ncomms2441)

Nickerson KM, Christensen SR, Shupe J, Kashgarian M, Kim D, Elkon K \& Shlomchik MJ 2010 TLR9 regulates TLR7- and MyD88-dependent autoantibody production and disease in a murine model of lupus. Journal of Immunology 184 1840-1848. (https://doi.org/10.4049/ jimmunol.0902592)

Nishimoto S, Fukuda D, Higashikuni Y, Tanaka K, Hirata Y, Murata C, Kim-Kaneyama JR, Sato F, Bando M, Yagi S, et al. 2016 Obesityinduced DNA released from adipocytes stimulates chronic adipose tissue inflammation and insulin resistance. Science Advances $\mathbf{2}$ e1501332. (https://doi.org/10.1126/sciadv.1501332)

Ohashi K, Parker JL, Ouchi N, Higuchi A, Vita JA, Gokce N, Pedersen AA Kalthoff C, Tullin S, Sams A, et al. 2010 Adiponectin promotes macrophage polarization toward an anti-inflammatory phenotype. Journal of Biological Chemistry 285 6153-6160. (https://doi. org/10.1074/jbc.M109.088708)

Revelo XS, Ghazarian M, Chng MH, Luck H, Kim JH, Zeng K, Shi SY, Tsai S, Lei H, Kenkel J, et al. 2016 Nucleic acid-targeting pathways promote inflammation in obesity-related insulin resistance. Cell Reports 16 717-730. (https://doi.org/10.1016/j.celrep.2016.06.024)

Schaffler A, Scholmerich J \& Buchler C 2005 Mechanisms of disease: adipocytokines and visceral adipose tissue--emerging role in nonalcoholic fatty liver disease. Nature Reviews Gastroenterology and Hepatology 2 273-280. (https://doi.org/10.1038/ncpgasthep0186)

Schaffler A, Muller-Ladner U, Scholmerich J \& Buchler C 2006 Role of adipose tissue as an inflammatory organ in human diseases. Endocrine Reviews 27 449-467. (https://doi.org/10.1210/er.2005-0022)

Schaffler A, Scholmerich J \& Salzberger B 2007 Adipose tissue as an immunological organ: toll-like receptors, C1q/TNFs and CTRPs. Trends in Immunology 28 393-399. (https://doi.org/10.1016/j. it.2007.07.003)

Shamseddeen H, Getty JZ, Hamdallah IN \& Ali MR 2011 Epidemiology and economic impact of obesity and type 2 diabetes. Surgical Clinics of North America 91 1163-1172, vii. (https://doi.org/10.1016/j. suc.2011.08.001)

Shi H, Kokoeva MV, Inouye K, Tzameli I, Yin H \& Flier JS 2006 TLR4 links innate immunity and fatty acid-induced insulin resistance. Journal of Clinical Investigation 116 3015-3025. (https://doi.org/10.1172/ JCI28898)

Stienstra R, Joosten LA, Koenen T, van Tits B, van Diepen JA, van den Berg SA, Rensen PC, Voshol PJ, Fantuzzi G, Hijmans A, et al. 2010 The inflammasome-mediated caspase- 1 activation controls adipocyte differentiation and insulin sensitivity. Cell Metabolism 12 593-605. (https://doi.org/10.1016/j.cmet.2010.11.011)

Takeshita F, Suzuki K, Sasaki S, Ishii N, Klinman DM \& Ishii KJ 2004 Transcriptional regulation of the human TLR9 gene. Journal of Immunology 173 2552-2561. (https://doi.org/10.4049/ jimmunol.173.4.2552) https://joe.bioscientifica.com https://doi.org/10.1530/JOE-18-0326
(C) 2019 Society for Endocrinology Published by Bioscientifica Ltd. Printed in Great Britain 
Takeuchi O \& Akira S 2010 Pattern recognition receptors and inflammation. Cell 140 805-820. (https://doi.org/10.1016/j. cell.2010.01.022)

Tilg H \& Moschen AR 2006 Adipocytokines: mediators linking adipose tissue, inflammation and immunity. Nature Reviews Immunology 6 772-783. (https://doi.org/10.1038/nri1937)

Varela-Guruceaga M, Milagro FI, Martinez JA \& de Miguel C 2018 Effect of hypoxia on caveolae-related protein expression and insulin signaling in adipocytes. Molecular and Cellular Endocrinology 473 257-267. (https://doi.org/10.1016/j.mce.2018.01.026)

Vijay-Kumar M, Aitken JD, Carvalho FA, Cullender TC, Mwangi S, Srinivasan S, Sitaraman SV, Knight R, Ley RE \& Gewirtz AT 2010 Metabolic syndrome and altered gut microbiota in mice lacking Toll-like receptor 5. Science $\mathbf{3 2 8}$ 228-231. (https://doi.org/10.1126/ science.1179721)

Wagner H 2001 Toll meets bacterial CpG-DNA. Immunity 14 499-502. (https://doi.org/10.1016/S1074-7613(01)00144-3)

Weisberg SP, McCann D, Desai M, Rosenbaum M, Leibel RL \& Ferrante AW Jr 2003 Obesity is associated with macrophage accumulation in adipose tissue. Journal of Clinical Investigation 112 1796-1808. (https://doi.org/10.1172/JCI200319246)
Welner RS, Pelayo R, Nagai Y, Garrett KP, Wuest TR, Carr DJ, Borghesi LA, Farrar MA \& Kincade PW 2008 Lymphoid precursors are directed to produce dendritic cells as a result of TLR9 ligation during herpes infection. Blood 112 3753-3761. (https://doi.org/10.1182/blood-200804-151506)

Wernstedt Asterholm I, Tao C, Morley TS, Wang QA, Delgado-Lopez F, Wang ZV \& Scherer PE 2014 Adipocyte inflammation is essential for healthy adipose tissue expansion and remodeling. Cell Metabolism 20 103-118. (https://doi.org/10.1016/j.cmet.2014.05.005)

Yu L, Yan K, Liu P, Li N, Liu Z, Zhu W, Chen Y \& Han D 2014 Pattern recognition receptor-initiated innate antiviral response in mouse adipose cells. Immunology and Cell Biology 92 105-115. (https://doi. org/10.1038/icb.2013.66)

Zaitsu H \& Serrero G 1990 Pedersen fetuin contains three adipogenic factors with distinct biochemical characteristics. Journal of Cellular Physiology 144 485-491. (https://doi.org/10.1002/ jcp.1041440316)

Zhang LJ, Guerrero-Juarez CF, Hata T, Bapat SP, Ramos R, Plikus MV \& Gallo RL 2015 Innate immunity. Dermal adipocytes protect against invasive Staphylococcus aureus skin infection. Science 347 67-71. (https://doi.org/10.1126/science.1260972)

Received in final form 29 November 2018

Accepted 30 November 2018

Accepted Preprint published online 3 December 2018
(C) 2019 Society for Endocrinology Published by Bioscientifica Ltd. 